\title{
Article \\ Role of Ajwa Date Fruit Pulp and Seed in the Management of Diseases through In Vitro and In Silico Analysis
}

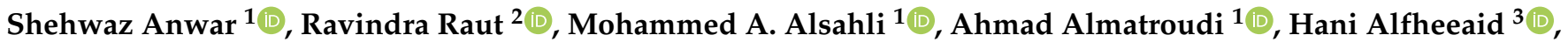 \\ Faisal M. Alzahrani ${ }^{4}\left(\mathbb{D}\right.$, Amjad Ali Khan ${ }^{5} \mathbb{D}$, Khaled S. Allemailem ${ }^{1, * \mathbb{D}}$, Saleh A. Almatroodi ${ }^{1}$ (D) \\ and Arshad Husain Rahmani ${ }^{1, *}$
}

check for updates

Citation: Anwar, S.; Raut, R.; Alsahli, M.A.; Almatroudi, A.; Alfheeaid, H.; Alzahrani, F.M.; Khan, A.A.;

Allemailem, K.S.; Almatroodi, S.A.; Rahmani, A.H. Role of Ajwa Date Fruit Pulp and Seed in the Management of Diseases through In Vitro and In Silico Analysis. Biology 2022, 11, 78. https://doi.org/ 10.3390/biology11010078

Academic Editors:

Almudena García-Ruíz, María del Mar Contreras and Merichel Plaza

Received: 9 December 2021

Accepted: 3 January 2022

Published: 5 January 2022

Publisher's Note: MDPI stays neutral with regard to jurisdictional claims in published maps and institutional affiliations.

Copyright: (C) 2022 by the authors. Licensee MDPI, Basel, Switzerland. This article is an open access article distributed under the terms and conditions of the Creative Commons Attribution (CC BY) license (https:// creativecommons.org/licenses/by/ $4.0 /)$
1 Department of Medical Laboratories, College of Applied Medical Sciences, Qassim University, Buraydah 51452, Saudi Arabia; shehwazanwar25@gmail.com (S.A.); shly@qu.edu.sa (M.A.A.); aamtrody@qu.edu.sa (A.A.); smtrody@qu.edu.sa (S.A.A.)

2 Department of Biotechnology, National Institute of Technology Durgapur, Durgapur 713209, India; raviraut206@gmail.com

3 Department of Food Science and Human Nutrition, College of Agriculture and Veterinary Medicine, Qassim University, Buraydah 51452, Saudi Arabia; h.alfheeaid@qu.edu.sa

4 Department of Clinical Laboratory Sciences, College of Applied Medical Sciences, Imam Abdulrahman Bin Faisal University, Dammam 31441, Saudi Arabia; fmzahrani@iau.edu.sa

5 Department of Basic Health Sciences, College of Applied Medical Sciences, Qassim University, Buraydah 51452, Saudi Arabia; akhan@qu.edu.sa

* Correspondence: k.allemailem@qu.edu.sa (K.S.A.); ah.rahmani@qu.edu.sa (A.H.R.)

Simple Summary: Most diseases result in an imbalance of antioxidant defense, inflammatory responses, and membrane permeabilization. The current therapeutic modules of disease prevention are not fully effective and have some adverse effects on physiological parameters. In this vista, medicinal plants and their active compounds have proven to be effective against disease prevention and treatment. Ajwa dates have high nutritional value and are reported to possess antioxidant, anti-inflammatory, and antitumor properties. In the current in vitro study, Ajwa fruit pulp and seed extract were found to have strong antioxidant properties, stabilize the RBC membrane, and have a good protective capacity against protein denaturation. Besides this, the seed extract prevents glucose-mediated browning of BSA as well as inhibiting the development of cross-amyloid and AGEs formations. Molecular docking results confirm the interaction between functional residues of antioxidant enzymes and components of Ajwa fruit pulp and seed contents. Therefore, the consumption of Ajwa dates can be beneficial in disease prevention and treatment. However, more detailed study is required based on pharmacological aspects to determine the mechanisms of action of Ajwa dates' components in disease prevention.

\begin{abstract}
This study investigated the health-promoting activities of methanolic extracts of Ajwa date seed and fruit pulp extracts through in vitro studies. These studies confirmed potential antioxidant, anti-hemolytic, anti-proteolytic, and anti-bacterial activities associated with Ajwa dates. The $E_{50}$ values of fruit pulp and seed extracts in methanol were reported to be $1580.35 \pm 0.37$ and $1272.68 \pm 0.27 \mu \mathrm{g} / \mathrm{mL}$, respectively, in the DPPH test. The maximum percentage of hydrogen peroxide-reducing activity was 71.3 and $65.38 \%$ for both extracts at $600 \mu \mathrm{g} / \mathrm{mL}$. Fruit pulp and seed extracts inhibited heat-induced BSA denaturation by 68.11 and $60.308 \%$, heat-induced hemolysis by $63.84 \%$ and $58.10 \%$, and hypersalinity-induced hemolysis by $61.71 \%$ and $57.27 \%$, and showed the maximum anti-proteinase potential of 56.8 and $51.31 \%$ at $600 \mu \mathrm{g} / \mathrm{mL}$, respectively. Seed and fruit pulp inhibited heat-induced egg albumin denaturation at the same concentration by 44.31 and $50.84 \%$, respectively. Ajwa seed showed minimum browning intensity by $63.2 \%$, percent aggregation index by $64.2 \%$, and amyloid structure by $63.8 \%$ at $600 \mu \mathrm{g} / \mathrm{mL}$. At $100 \mathrm{mg} / \mathrm{mL}$, Ajwa seed extract exhibited good antibacterial activity. Molecular docking analysis showed that ten active constituents of Ajwa seeds bind with the critical antioxidant enzymes, catalase (1DGH) and superoxide dismutase (5YTU). The functional residues involved in such interactions include Arg72, Ala357, and Leu144 in 1DGH, and Gly37, Pro13, and Asp11 in 5YTU. Hence, Ajwa dates can be used to develop a suitable alternative therapy in various diseases, including diabetes and possibly COVID-19-associated complications.
\end{abstract}


Keywords: Ajwa; antidiabetic; anti-inflammatory; antioxidant; anti-hemolytic; oxidative stress; molecular docking

\section{Introduction}

Inflammation and hyperglycemia have been found to be two significant pathologies associated with the severity of various diseases and increasing death rates across the world. All the diseases are linked with increased inflammatory biomarkers and cytokines [1]. Insulin resistance, hyperglycemia, and cell death are all caused by changes in the shape and function of $\beta$ cells and endothelial cells as a consequence of cytokine release [2]. In addition, diseases involving severe liver tissue damage decrease glycogen production and increase insulin tolerance and hyperglycemia. As a result, treating hyperglycemia will result in a decrease in serum levels of cytokine [3].

The accumulation of different reactive oxygen species (ROS) is an indicator of oxidative stress [4]. ROS are very active oxidant molecules with an additional electron. Overproduction of superoxide ions leads to activation of five key pathways linked to diabetic complications, such as polyol pathway flux, protein kinase $\mathrm{C}$ activation, agitation of the hexosamine pathway, increased production of advanced glycation end products (AGEs), as well as increased expression of AGE receptors and their activating ligands [5]. Constant hyperglycemia along with diabetic conditions damages various organs and leads to various macrovascular complications such as premature atherosclerosis, myocardial infarctions, peripheral vascular disease, as well as microvascular complications such as nephropathy, neuropathy, and retinopathy. AGEs are covalent products of nonenzymatic glycation and oxidation of various biomolecules [6]. AGEs have been reported to be involved in the pathology of various diseases such as diabetes, inflammation, neurodegeneration, and aging. Thus, checking the formation and accumulation of AGEs can be a plausible move for treatment/prevention of these disorders [7].

A complex system of antioxidant molecules and enzymes works provides protection against oxidative stress by preventing the excess of ROS, neutralizing the free radicals, and restoring the damage caused by ROS. It has been established that damage to this defense system, and, hence, increased oxidative stress, has been linked to various disorders [8] and pathogenesis, mortality risk, and severity in patients with SARS-CoV infection [9]. Glycation-mediated inactivation of antioxidant enzymes such as superoxide dismutase can disrupt the cellular antioxidant defense system that contributes to a variety of pathologies linked with long-term diabetic complications [10-14].

While numerous off-label medicines have shown encouraging results in the treatment of so many commonly found diseases, there is currently no complete licensed therapy possible to treat these diseases and disorders. As a result, there is a great need for possible medical remedies or the use of off-label medicines in this situation. As a result, it is important to investigate alternative medicine, such as folk medicine, as an alternative to traditional diabetic treatments and other related diseases. Herbal drugs with antioxidant potential and scientifically proved benefits in the treatment of diabetes mellitus may be recommended as a complementary therapy of traditional treatments for COVID patients [15].

Different varieties of date palm (Phoenix dactylifera) are consumed in Arab areas for centuries due to their excellent nutritional properties. Ajwa dates from Saudi Arabia have been documented to be a rich source of antioxidants and other nutritious components [16] (Figure 1). Besides, date palms have been well claimed to possess potent hepato-protective, nephroprotective, anticancer, antidiabetic, anti-ulcerative, and antihypertensive properties. Moreover, all varieties of date including Ajwa have exhibited antioxidant and antitumor properties [17]. 


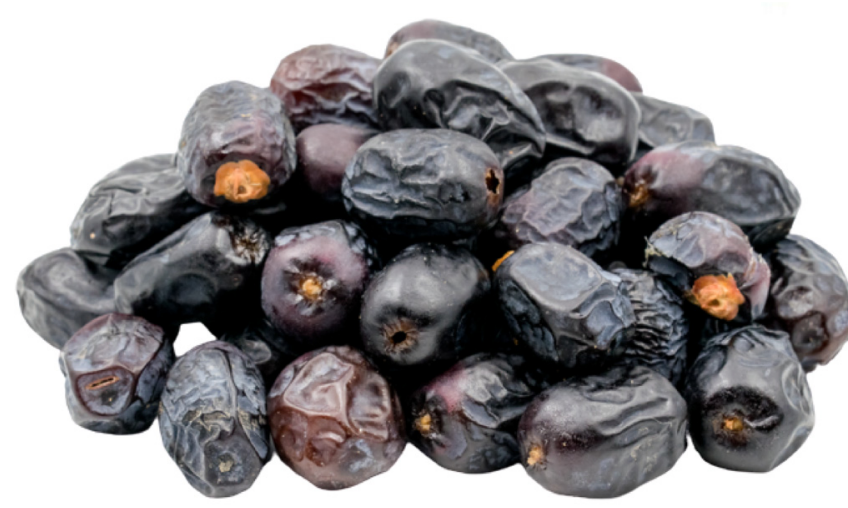

Ajwa dates

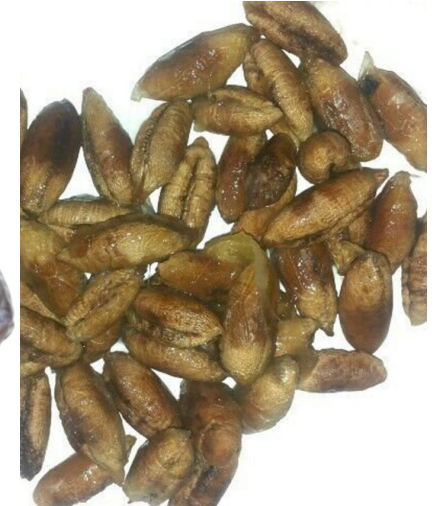

Ajwa date seeds

Figure 1. Ajwa dates and their seeds.

Molecular docking is indeed a type of in silico modeling in which two or more molecules combine to form a stable adduct. Docking suggests the three-dimensional structure of any complex based on the binding characteristics of target molecules (protein, DNA, etc.) and ligand. It generates a variety of potential adduct structures, which are scored and classified using the software's scoring algorithm. Based on the overall energy of the system, docking simulations indicate the best suitable docked conformers. The goal is to predict the bound conformations and the binding affinity [18].

The goal of our study was to investigate in vitro health beneficial capabilities of methanolic extract of Ajwa date seed and fruit pulp to explore a possible alternative strategy against the inhibition of pathogenesis mortality of diabetic patients afflicted with COVID-19. The molecular docking studies with superoxide dismutase and catalase and Ajwa compounds were conducted to investigate possible antioxidant potential of Ajwa in preventing oxidative stress and relate the most promising molecules of Ajwa to their chemical characteristics.

\section{Materials and Methods}

\subsection{Materials}

Trichloroacetic acid, trypsin, 2,2-diphenyl-1-picrylhydrazyl (DPPH), gallic acid, ferric chloride, Folin-Ciocalteu reagent, ascorbic acid, potassium ferricyanide, quercetin, and Congo red were obtained from Sigma Co. St. Louis, MO, USA. Disodium hydrogen phosphate, hydrochloric acid, DMSO, mono sodium dihydrogen phosphate, aluminum chloride, ethanol, methanol, sodium carbonate, sodium hydroxide, and hydrogen peroxide have been received from Merck, Darmstadt, Germany. Analytical-grade chemicals and reagents were used, whereas the solvents were of HPLC grade in current study.

\subsection{Preparation of Extracts}

The methanol extracts of Ajwa seed and fruit pulp were obtained following our standardized procedure. In a nutshell, the seeds and pulp were detached and properly cleaned with distilled water. They were dried thoroughly afterwards. To create the powder, the dry ingredients were finely ground. To grind the seed, a mortar and pestle were employed followed by use of an electronic mixer grinder. The methanol samples were obtained via soaking approximately $100 \mathrm{~g}$ of plant stuff in powder form independently in 1 liter of $97 \%$ methanol, in a magnetic shaker over three hours at $37^{\circ} \mathrm{C}$. The extracts were purified by filtration before being condensed using rotary evaporators at decreased pressure and $40{ }^{\circ} \mathrm{C}$ to obtain raw active component. Both extracts were kept at $4{ }^{\circ} \mathrm{C}$ for future analysis. The \% yield of extract was calculated using the equation below [19]. 


\subsection{Phytochemical Screening}

A previously published paper was used to conduct phytochemical screening of carbohydrates, phenolics, alkaloids, saponins, flavonoids, tannins, anthraquinone, as well as phenolic compounds [20]. Carbohydrate detection was accomplished through mixing $1000 \mu \mathrm{L}$ of iodine solution and $3000 \mu \mathrm{L}$ of seed and fruit pulp extracts prepared in methanol separately. Carbohydrates could be confirmed if the color turned to purple. The existence of saponins was determined by mixing $5 \mathrm{~mL}$ of distil water with $5 \mathrm{~mL}$ of extracts in a test tube and aggressively shaking the mixture before warming the test tube. The presence of saponins is indicated by the development of stable froth. Meanwhile, $2000 \mu \mathrm{L}$ of extracts and $2000 \mu \mathrm{L}$ of distil water were mixed in a vial. The condensed tannins were indicated by the formation of green precipitate after adding a few drops of $\mathrm{FeCl}_{3}$. The availability of flavonoids in both extracts were verified by that of the development of a strong yellow color when $2 \mathrm{~mL}$ of extracts were mixed with a $20 \%$ sodium hydroxide solution. However, after the addition of dilute $\mathrm{HCl}$, the yellowish color becomes colorless. When a few drops of $\mathrm{FeCl}_{3}$ were combined with the extracts, the development of such a blue black color reported the existence of phenolic chemicals.

\subsection{Evaluation of Phenolic Content}

Within this experiment, extracts of seed and fruit pulp $(0.500 \mathrm{~mL}, 1000 \mu \mathrm{g} / \mathrm{mL})$ were placed separately in various test tubes containing $2500 \mu \mathrm{L}$ of Folin-Ciocalteu reagent (10\%). Then, $2000 \mu \mathrm{L}$ of sodium carbonate $(7.5 \%)$ was eventually added to all tubes. The tubes were maintained at $37^{\circ} \mathrm{C}$ in the absence of light for $30 \mathrm{~min}$. After incubation, the absorbance of various solutions was recorded with a spectrophotometer at $760 \mathrm{~nm}$. Various concentrations of gallic acid $(50-250 \mathrm{~g} / \mathrm{mL})$ were used to construct a standard curve plot. The phenolic contents of both extracts were calculated using this standard curve. Phenolic contents of extracts were evaluated in milligram (GAE). All of the experiments tests were conducted twice. The results were expressed as mg equivalents of gallic acid per gm sample extract. The following formula was used to calculate total phenolic content [19]:

$$
\text { Total phenolic content }=\mathrm{K} \times \mathrm{Vol} / \mathrm{w}
$$

where Vol is the volume $(\mathrm{mL})$ of sample used in the extraction. $\mathrm{K}$ is the concentration of gallic acid in $\mathrm{mg} / \mathrm{mL}$, and $\mathrm{w}$ is the weight of pure dried sample used $(\mathrm{g})$.

\subsection{Evaluation of Flavonoid Contents in Extracts}

The flavonoid contents of both extracts were estimated using the method described in our prior article [19]. Quercetin $(20,25,50,75,100,150,200$, and $250 \mu \mathrm{g} / \mathrm{mL})$ was employed to create a standard plot. In a nutshell, $500 \mu \mathrm{L}$ of quercetin solution or extract $(50 \mu \mathrm{g} / \mathrm{mL})$ were added to a vial having $\mathrm{AlCl}_{3}$ solution ( $500 \mu \mathrm{L}, 2 \%$ ). Intermittent mixing of the vials was done. The absorbance of each solution was measured at $420 \mathrm{~nm}$ spectrophotometrically against methanol (blank) after $1 \mathrm{~h}$ of incubation of tubes at room temperature. Flavonoid contents of extracts were expressed as milligram quercetin equivalent per gram sample extract (mg QUE/g). To evaluate the flavonoid contents of both extracts, the following equation was employed:

$$
\mathrm{TFC}=\mathrm{K} \times \mathrm{Vol} / \mathrm{w}
$$

where $\mathrm{Vol}$ is the volume of plant extract $(\mathrm{mL}) . \mathrm{K}$ is the concentration of quercetin $(\mathrm{mg} / \mathrm{mL})$, and $\mathrm{w}$ is the weight of the pure dried sample used $(\mathrm{g})$.

\subsection{Reducing Capacity Assessment}

This assay was performed as per the method described in prior articles with slight changes $[19,20]$. Actually, it measured the potential of extracts to convert more oxidized ferric ions into lesser oxidized ferrous ions at room temperature. This reaction resulted in the change of absorbance monitored at $700 \mathrm{~nm}$ for both control and test samples against 
phosphate buffer $(\mathrm{pH}$ 6.6) only. All of the assays were done thrice. The percentage reducing capacity was calculated using the formula provided below [19].

$$
\text { Percentage reducing ability }=[(\mathrm{Zc}-\mathrm{Zs}) / \mathrm{Zc}] \times 100
$$

where $\mathrm{Zc}$ denotes the absorbance of the control (solution not having any extract) and $\mathrm{Zs}$ indicates the absorbance of extract containing solution.

\subsection{Scavenging of Hydrogen Peroxide $\left(\mathrm{H}_{2} \mathrm{O}_{2}\right)$}

This activity was investigated as per the method described in prior researchers with slight changes $[19,21]$. The extracts $(100,200,300,400,500$, and $600 \mu \mathrm{g} / \mathrm{mL})$ or ascorbic acid were mixed separately with $1000 \mu \mathrm{L}$ of $\mathrm{H}_{2} \mathrm{O}_{2}$ solution ( $40 \mathrm{mM}$ prepared in phosphate buffer $\mathrm{pH}$ 7.4). The absorbance of all samples was determined at $230 \mathrm{~nm}$ after $10 \mathrm{~min}$ of incubation of tubes against phosphate buffer. All the experiments were done three times. The hydrogen peroxide percentage scavenging potential was then evaluated using the following equation. The percentage of scavenged $\mathrm{H}_{2} \mathrm{O}_{2}$ was calculated by the formula provided below [19].

$$
\mathrm{H}_{2} \mathrm{O}_{2} \text { scavenging ability }(\%)=[(\mathrm{Zc}-\mathrm{Zs}) / \mathrm{Zc}] \times 100
$$

where $\mathrm{Zc}$ indicates the absorbance of $\mathrm{H}_{2} \mathrm{O}_{2}$ solution. $\mathrm{Zs}$ denotes the absorbance of the solution having both $\mathrm{H}_{2} \mathrm{O}_{2}$ and extract.

\subsection{DPPH Assay}

The antioxidant activity was further confirmed on the basis of scavenging 1,1 difenyl-2picryl-hydrazyl (DPPH) as described in prior articles [19,22,23]. Briefly, $2.5 \mathrm{~mL}$ of increasing concentration of methanolic extracts $(50,100,200,300,400,500$, and $600 \mu \mathrm{g} / \mathrm{mL})$ was mixed with DPPH (1 mL, $0.3 \mathrm{mM}$; prepared in analytical grade methanol). The absorbance of each solution was noted at $517 \mathrm{~nm}$ followed by $30 \mathrm{~min}$ incubation of each solution against methanol. However, control contained DPPH in methanol for this assay.

$$
\text { Percentage DPPH scavenging activity }=[(Z c-Z s) / Z c] \times 100)
$$

where $\mathrm{Zc}$ indicates the absorbance of solution without extract. Zs denotes the absorbance of the solution having extract.

\subsection{Albumin Denaturation Inhibition Activity}

Evaluation of anti-inflammatory potential of both extracts was evaluated by inhibition of albumin denaturation as described earlier $[19,24,25]$ with slight modifications. Ibuprofen was used as a reference drug for this experiment. The test solution contained $500 \mu \mathrm{L}$ of $1 \%$ aqueous solution of bovine serum albumin (BSA) as well as $100 \mu \mathrm{L}$ of extracts (100, $200,300,40,500$, and $600 \mu \mathrm{g} / \mathrm{mL}$ ) or $200 \mu \mathrm{g} / \mathrm{mL}$ of non-steroidal anti-inflammatory drug ibuprofen in separate tubes. Samples were taken out from the incubator after incubation for $20 \mathrm{~min}$ at $37^{\circ} \mathrm{C}$. The solutions were heated at $71^{\circ} \mathrm{C}$ for $10 \mathrm{~min}$ to denature the protein. After cooling, the turbidity of samples was spectrophotometrically recorded at $660 \mathrm{~nm}$, against distil water. The tests were done three times. The inhibition of BSA denaturation (\%) was determined using the formula provided below [19].

$$
\text { Percent inhibition }=[(\mathrm{Zc}-\mathrm{Zs}) / \mathrm{Zc}] \times 100
$$

where Zc indicates the absorbance of control. Zs indicates the absorbance of the sample containing extract or ibuprofen.

\subsection{Inhibition of Proteinase Action}

The methodology followed by Anwar et al. (2020a) [19] and Sakat et al. (2010) [25] was used to test the inhibitory action of Ajwa date on trypsin. The testing solutions $(2000 \mu \mathrm{L})$ 
had $1000 \mu \mathrm{L}$ of tris $\mathrm{HCl}$ buffer $(20 \mathrm{mM}$; $\mathrm{pH} 7.4)$, trypsin $(60 \mu \mathrm{g})$, and $1000 \mu \mathrm{L}$ of varying concentration of extracts $(100,200,300,400,500$, and $600 \mu \mathrm{g} / \mathrm{mL})$ or $0.20 \mathrm{mg} / \mathrm{mL}$ of diclofenac sodium. After $5 \mathrm{~min}$ at room temperature, $1000 \mu \mathrm{L}$ of casein $(0.8 \%)$ was added to the tubes. The tubes were kept at room temperature for $5 \mathrm{~min}$, and $1 \mathrm{~mL}$ of casein $(w / v)$ was added. To cease the reaction, $2000 \mu \mathrm{L}$ of $70 \%$ perchloric acid was included after $20 \mathrm{~min}$ that resulting in the formation of a cloudy solution. The centrifugation was carried out at $2500 \mathrm{rpm}$ for $5 \mathrm{~min}$. At $210 \mathrm{~nm}$, the supernatant's absorbance was tested against a blank containing just a buffer. Triplicates of each sample were taken.

$$
\text { Percentage inhibition of proteinase action }(\%)=[(Z c-Z s) / Z c] \times 100
$$

where Zc signifies the absorbance of a control sample, and Zs denotes the absorbance of the sample having either the extract or diclofenac.

\subsection{Inhibition of Egg Albumin Denaturation}

Phosphate buffer saline ( $2800 \mu \mathrm{L}, \mathrm{pH} 6.4)$, raw egg albumin of hen $(200 \mu \mathrm{L})$, and $2000 \mu \mathrm{L}$ of different concentrations $(100,200,300,400,500$, and $600 \mu \mathrm{g} / \mathrm{mL})$ of extracts were taken in the reaction solution $(5 \mathrm{~mL})[24,25]$. Diclofenac sodium was used as a standard drug $(200 \mu \mathrm{g} / \mathrm{mL})$. In a BOD incubator, various tubes containing these solutions were kept for $15 \mathrm{~min}$ at $37 \pm 2{ }^{\circ} \mathrm{C}$. The reaction mixtures were then heated for $5 \mathrm{~min}$ at $70^{\circ} \mathrm{C}$. After cooling, their absorbance was taken at $660 \mathrm{~nm}$ spectrophotometrically against buffer phosphate saline. The formula provided below was used to determine the percentage egg albumin denaturation inhibition.

$$
\text { Percentage Inhibition }=[(\mathrm{Zc}-\mathrm{Zs}) / \mathrm{Zc}] \times 100
$$

where $\mathrm{Zc}$ signifies the absorbance of a control sample, and Zs denotes the absorbance of the sample having either the extract or diclofenac.

\subsection{Assessment of Potential of Membrane Stabilization \\ a Preparation of Red Blood Cell (RBC) Suspension}

A healthy and fit volunteer gave a fresh blood sample after fourteen days of not using any anti-inflammatory (non-steroidal) or anti-contraceptive drugs. The blood samples were then shifted to vials containing the same amount of sterilized Alsever's solution as the blood sample. The resulting solutions were subsequently centrifuged for $10 \mathrm{~min}$ at $3000 \mathrm{rpm}$. The erythrocyte sediments were washed three times using an equal volume of normal saline after the discarding of supernatant plasma. The volume of each resultant was determined and isotonic phosphate buffer ( $\mathrm{pH}$ 7.4) was employed to reconstitute RBC suspension $(10 \% v / v)[19,26]$.

\section{$b \quad$ Heat Induced Hemolysis}

Heat-induced erythrocyte hemolysis was carried out as detailed in our earlier articles [19] with a few changes. Then, $1000 \mu \mathrm{L}$ of extract (100, 200, 300, 400, 500, and $600 \mu \mathrm{g} / \mathrm{mL})$ or aspirin $(200 \mu \mathrm{g} / \mathrm{mL})$ was combined with $1000 \mu \mathrm{L}$ of previously prepared RBC solution $(10 \% v / v)$. For $20 \mathrm{~min}$, all of the tubes were kept in a water bath at $56^{\circ} \mathrm{C}$. After incubation, different tubes were removed from the water bath and were cooled. The tubes were centrifuged for $5 \mathrm{~min}$ at $2500 \mathrm{rpm}$ and $4{ }^{\circ} \mathrm{C}$. At $540 \mathrm{~nm}$, the absorbance of resultant supernatants was measured using a spectrophotometer. The control had buffer and RBC suspension (without drug or extract), whereas the blank used phosphate buffer only. The percentage protection against hemolysis induced by heat was estimated using the formula provided below.

$$
\text { Percentage protection }=[(\mathrm{Zc}-\mathrm{Zs}) / \mathrm{Zc}] \times 100
$$

where $\mathrm{Zc}$ signifies the absorbance of a control sample, and Zs denotes the absorbance of the sample having either the extract or aspirin. 


\section{c Inhibition of Hyposaline Induced Hemolysis}

Hyposaline-induced erythrocyte hemolysis was carried out as detailed by earlier articles $[19,26]$ with a few changes. Then, $1000 \mu \mathrm{L}$ of phosphate buffer (pH 7.4, 0.1 M), hyposaline $(2000 \mu \mathrm{L})$, and $500 \mu \mathrm{L} \mathrm{RBC}$ suspension $(10 \% v / v)$ were mixed with $1 \mathrm{~mL}$ of varying concentration of extracts $(100,200,300,400,500$, and $600 \mu \mathrm{g} / \mathrm{mL})$ or diclofenac $(200 \mu \mathrm{g} / \mathrm{mL})$. The control solution, on the other hand, used distil water in the place of hyposaline, and there was neither drug nor extract. At $37^{\circ} \mathrm{C}$, all tubes were incubated for $30 \mathrm{~min}$. After the incubation period, the tubes were centrifuged for $10 \mathrm{~min}$ at $3000 \mathrm{rpm}$. At $560 \mathrm{~nm}$, the absorbance of the collected supernatant was determined. By assuming 100\% hemolysis in the control, the percent protection from hyposalinity-induced hemolysis was evaluated [19].

$$
\text { Percentage protection }=100-[(\mathrm{Zs} / \mathrm{Zc}) \times 100]
$$

where Zc signifies the absorbance of a control sample, and Zs denotes the absorbance of the sample having either the extract or diclofenac.

\subsection{Screening of Antiglycating and AGEs Formation Inhibiting Potential \\ a Incubation of Extracts with In Vitro Glycation System}

Brownlee's methodology was applied with minor changes [27]. Only Ajwa seed extract was used in antiglycation and AGEs formation inhibition study. In this experiment, glucose $(500 \mathrm{mM})$ and BSA $(10 \mathrm{mg} / \mathrm{mL})$ were combined with or without Ajwa seed extract $(100,200,300,400,500$, and $600 \mu \mathrm{g} / \mathrm{mL})$ in phosphate buffer $(0.1 \mathrm{M}, \mathrm{pH} 7.4)$. The mixtures were stored at room temperature for 15 days on a shaker away from direct sunlight. The incubated samples were subsequently dialyzed overnight at $37^{\circ} \mathrm{C}$ against phosphate buffer (50 mM, pH 7.4) to eliminate unbound glucose. The dialysis of the incubated samples was done to eliminate unbound glucose at $37^{\circ} \mathrm{C}$ using phosphate buffer $(50 \mathrm{mM}, \mathrm{pH} 7.4)$ for the whole of the night. The concentration of BSA in each sample was calculated using the molar extinction coefficient. The samples were immediately kept at $-20^{\circ} \mathrm{C}$ for further use. Each sample was treated with $3 \mathrm{mM} / \mathrm{L}$ of sodium azide to avoid bacterial contamination. All of the trials were repeated three times.

\section{$b \quad$ Assessment of Browning Intensity}

Glycation has been reported to have a significant role in diabetes and its complications [4]. The browning intensity of glycated samples has been found to be an indicator of glycation of various samples [19]. The intensity of browning was screened by recording the absorbance of different glycated samples at $420 \mathrm{~nm}$ [28] using a 1-cm path length cell after diluting with distill water. All the experiments were carried in triplicates. The relative percentage browning intensity was determined by the formula given below [19].

$$
\text { Percentage protection from browning }=[(\mathrm{Zc}-\mathrm{Zs}) / \mathrm{Zc}] \times 100
$$

where $\mathrm{Zc}$ indicates the absorbance of glycated samples without extract. Zs denoted absorbance of glycated samples having seed extract.

\section{c Effect on Protein Aggregation Index}

Glycation induces the structural alterations in biomolecules such as proteins. The structural abnormality may lead to the formation of aggregates. Protein aggregate formation is further linked to various diseases and their complications. Therefore, it is very necessary to investigate the protective activity of natural products against glycation induced protein aggregates formation to develop a strategy for the treatment and management of diseases linked with aggregate formation. The protective ability of Ajwa seed extract was investigated by recording the absorbance of different glycated samples either having seed extract 
$(100,200,300,400,500$, and $600 \mu \mathrm{g} / \mathrm{mL})$ or not having seed extract. The aggregation index was calculated by the following formula

Percentage of protein aggregation index $=\left[\mathrm{A}_{340} /\left(\mathrm{A}_{280}-\mathrm{A}_{340}\right)\right] \times 100$

where $\mathrm{A}_{340}=$ Absorbance at $340 \mathrm{~nm}$ and $\mathrm{A}_{280}=$ Absorbance at $280 \mathrm{~nm}$.

d Percent Inhibition of Fibrillar State: Congo Red Assay

Congo red assay was performed to evaluate the percent inhibition of glycation-induced fibrillation of BSA. The CR assay is based on the capacity of dye binding with fibrils [29]. Congo red (amyloid specific dye) was prepared according to previously published articles $[19,28]$. The absorbance was measured for different samples such as AGE-BSA with seed extract only $(100,200,300,400,500$, and $600 \mu \mathrm{g} / \mathrm{mL})$, AGE-BSA, and native BSA separately, as well as for the background of Congo red. In short, $500 \mu \mathrm{L}$ of glycated protein solution/native BSA $(100 \mu \mathrm{M})$, and $100 \mu \mathrm{L}$ of Congo red $(100 \mu \mathrm{M})$ were incubated at room temperature for $10 \mathrm{~min}$. The absorbance of each sample was measured at $530 \mathrm{~nm}$.

$$
\% \text { inhibition of amyloid formation }=[(\mathrm{Zc}-\mathrm{Zs}) / \mathrm{Zc}] \times 100
$$

where $\mathrm{Zc}$ is the measured absorbance of BSA and glucose system that does not have extract. $\mathrm{Zs}$ is the absorbance of BSA and glucose system incubated with seed extract or BSA not incubated with glucose or extract.

\subsection{Antimicrobial Activity}

The antimicrobial potential of extracts was evaluated using five strains of bacteria and one strain of fungal. Gram-positive cocci included Enterococcus faecalis ATCC 29212 and Staphylococcus aureus ATCC 29213. Gram-negative bacilli listed Escherichia coli ATCC 25922, Pseudomonas aeruginosa ATCC 27853, and Klebsiella pneumonia ATCC 700603). All strains were obtained as a gift from the Microbiology lab, College of Applied Medical Sciences, Qassim University, and KSA.

\subsection{Dilutions and Inoculum Preparations}

Bacterial and fungal inoculum from fresh pure cultures were prepared using Muller Hinton broth, and 0.5 McFarland standard was used for comparison of each bacterial and fungal suspension. Two concentrations of extracts $(25$ and $50 \mathrm{mg} / \mathrm{mL}$ ) were prepared by serial dilution of seed and pulp extracts stock solution in sterile distilled water.

\subsection{Procedure for Performing the Well Diffusion Test}

Agar well diffusion assay was performed to investigate the antimicrobial activity against the selected microorganisms [20]. A sterile cotton swab was used for the spreading procedure. The backside of blue micropipette tips was used to make two wells in the agar plate with the bottom of wells having melted MHA agar for sealing. Two different concentrations of extracts were included in different wells. The positive controls were Erythromycin 15, Vancomycin 30, Imipenem 30, Amikacin 30, and Fluconazole 10. After incubation for 1 day at $37^{\circ} \mathrm{C}$, the zone of inhibition around the wells was investigated. A ruler was used to record the zone diameter in millimeters $(\mathrm{mm})$.

The lowest antimicrobial concentration that completely inhibited the bacterial growth in all replicate wells was used to calculate the MIC (minimum inhibitory concentration). A plot of bacterial growth vs. extract concentration was found very steep to estimate IC50 accurately. As a result, the MIC was employed for bacteria in this experiment. By dissolving the extract in nutritional broth, several quantities of Ajwa seed extracts (500, 250, 125, 100, 50,25 , and $6.25 \mathrm{mg} / \mathrm{mL}$ ) were prepared individually. The bacterial solution was adjusted to $1.5 \cdot 10^{-8} \mathrm{CFU}$ at McFarland standard and diluted to 1:100. To calculate the MIC, $50 \mu \mathrm{L}$ of the various extract concentrations was mixed with $50 \mu \mathrm{L}$ of the bacterial suspensions on sterile 96-well plate nutrient agar (Oxoid) (Corning Costar Ltd., Tewksbury, MA, USA). The plates 
were then incubated for 16 to $20 \mathrm{~h}$ at $35^{\circ} \mathrm{C}$. The MIC was determined by taking the lowest concentration of extract in the well with no bacterial growth (indicated as no turbidity).

\subsection{Statistical Analysis}

All the experiments were carried out in triplicate, expressed as means \pm standard error. The statistical analysis was performed using ANOVA. The probability, $p<0.05$ was considered as statistically significant for a test.

\section{Docking Studies}

\subsection{The Receptors}

For the present study, two very important enzymes of the cellular anti-oxidant mechanism, viz. catalase, and superoxide dismutase (SOD), were selected for the prediction of possible interaction of the constituents and metabolites of Ajwa date seed extract. Any interaction between residues of enzymes and these constituents might contribute to possible protection against glycation or oxidative stress-induced denaturation of these enzymes. Three-dimensional structures of human erythrocyte catalase 3-amino-1,2,4-triazole complex (PDB id: 1DGH) human SOD 1 complexed with isoproterenol (PDB id: 5YTU) were downloaded from the Protein Databank website (https: / / www.rcsb.org/, last accessed on 18 June 2021) in the .pdb formats. The two structures are crystal structures determined using X-ray diffraction at resolutions of 2 and $1.9 \AA$, respectively. Selection of the structures was based on resolution, source organism, and availability of bound ligand for reference of the active site, and the residues of the active site.

\subsection{The Ligands}

It was found that 3,30-di-O-methyl ellagic acid, 7-methoxyquercetin-O-hexose isomers, caffeic acid, ferulic acid, quercetin-rutinoside, $6^{\prime \prime \prime}$-malonylicariin, p-hydroxybenzoic acid, phytol, punicalagin, and quercetin-3-O-glucoside (isoquercitrin) are active constituents of date fruit. Three-dimensional structures of all the ligands were downloaded from the NCBI PubChem compound database (https:/ / pubchem.ncbi.nlm.nih.gov/, last accessed on 18 June 2021) in the .sdf formats. Details of the ligands with their properties are provided in the result section with the sub-heading Receptor-Ligand Interaction Study by Molecular Docking.

Since three-dimensional conformers of $6^{\prime \prime \prime}$-malonylicariin and punicalagin are not available in the NCBI PubChem compound database, two-dimensional conformers, bearing ID 135398032 and 44584733, were downloaded from the database. Then these structures were converted to three-dimensional conformers using Web-based SMILES Translation Service; Online SMILES Translator and Structure File Generator (https:/ / cactus.nci.nih. gov/translate/, last accessed on 18 June 2021).

\subsection{Molecular Docking}

Molecular docking is a powerful computational modeling tool in evaluating the binding of a ligand (phytochemicals or others) to the active site of an enzyme or receptor. Molecular docking was performed for identifying the interaction between substrate and enzyme. The structure of ligands was collected from the PubChem database [30]. AutoDock vina [31] was used for docking, and the protein was prepared accordingly in BIOVIA Discovery Studio Visualizer (https:/ / discover.3ds.com/discovery-studio-visualizer-download/, accessed on 18 June 2021) [32]. All water molecules available with the receptors were removed from the workspace.

The grid sizes of the docking were center_x $=25.591047$, center_y $=40.102372$, center_Z $=60.221023$ along the size 20 for $X, Y$, and Z-axis for 1DGH and center_ $x=-76.243300$, center_y $=6.146800$, center_ $\mathrm{Z}=-3.292600$, respectively, along the size 20 for $X, Y$, and Z-axis for $5 Y T U$, respectively. Before performing the docking experiment, polar hydrogens were added to each protein receptor, and Kollman's partial atomic charges were applied to minimize the energy. The processed structure of receptors was saved in PDBQT file format, 
which contains hydrogens in all polar residues. MGL tools (https://ccsb.scripps.edu/ mgltools /downloads /, last accessed on 20 June 2021) were used to process the receptor and ligands by adding hydrogen atoms [33]. The maximum number of runs was set to 8 . The best docking in terms of free energy of binding (expressed as negative values) was considered for further analysis.

\section{Results}

Ajwa dates are consumed quite often in Gulf countries as they possess some excellent nutritious components with antioxidant properties. It has been reported that Ajwa dates play a significant role in the management of different diseases through the modulation of various biological activities. In this study, the role of Ajwa dates, pulp, and seeds in disease management was explored through in vitro and in silico analysis.

The DPPH approach is the most often used in vitro antioxidant activity measurement, whereas lipid peroxidation approach is the most widely utilized in vivo antioxidant activity evaluation [34]. The screening for antioxidant potential necessitates the use of methods that focus on the kinetics of reactions that include antioxidants and address the mechanism of antioxidant activity. It has been seen that methods based on suppressed autoxidation are best for termination-enhancing and chain-breaking antioxidants. On the other hand, distinct particular investigations are needed for preventative antioxidants [35]. Oxidative stress, systemic hyper-inflammatory reactions, glycation of biomolecules, advanced glycation endproduct formation, and permeabilization of the lysosomal membrane are all very commonly linked to a range of diseases such as diabetes and its complications. Our study indicated the strong antioxidant potential of Ajwa dates that may link the therapeutic potential of the Ajwa date against oxidative stress, denaturation of proteins, stability of membranes, as well as AGE formation. Preliminary phytochemical analysis of the methanolic extract of Ajwa revealed the presence of different biomolecules.

\subsection{Preliminary Screening, Flavonoid, and Phenolic Content}

Ajwa dates are usually black in color, and are most commonly cultivated in Medina, Saudi Arabia (Figure 1). The color, odor, texture, and the yield (percentage) of methanol extracts of Ajwa seed as well as fruit pulp extract are provided in Table 1. The results of phytochemical screening of Ajwa fruit pulp and seed extract for the presence of different phytoconstiuents are provided in Table 2. Further, TPC in fruit pulp and seeds extracts were $245.30 \pm 0.046$ and $195.54 \pm 0.046 \mathrm{mg}$ gallic acid equivalent/g dry weight of each extract, respectively. Reducing sugars, particularly fructose, ascorbic acid, and protein, may have an effect on the quantity of total polyphenols. Polyphenols contribute to health-promoting and sensorial properties of fruits and vegetables. Further, polyphenols are responsible for varying structure-dependent stability during processing and shelf-life [36].

The protective role of flavonoids has been reported to be against diabetes and its complications, cancer, and cardiovascular diseases. TFC in ethanol extracts of fruit pulp as well as seed were $43.58 \pm 0.010$ and $35.28 \pm 0.180 \mathrm{mg}$ quercetin equivalents/g dry weight of extract.

LC-MS analysis conducted by Khan and coworkers revealed the presence of various phytocomponents in Ajwa date pulp extract belonging to classes such as carbohydrates, phenolics, flavonoids, and terpenoids. Maltose, catechin, myricetin, quercetin, $\beta$-sitoserol, digalacturonic acid, chlorogenic acid, and $\beta$-carotene were found to be major molecules [37]. Moreover, the LC-linear ion quadrupole mass spectrometric analysis (LC-MS and LC-MS/MS tandem mass spectrometry) analysis revealed the presence of 3,30-di-O-methyl ellagic acid, 7-methoxyquercetin-O-hexose isomers, caffeic acid, ferulic acid, isomers of quercetin-rutinoside, kaempferol methylether, p-hydroxybenzoic acid, phytol, punicalagin, and quercetin-3-O-glucoside (isoquercitrin) in Ajwa [38]. The most dominant phenolic compounds in Ajwa dates, according to Hamad et al. (2015) [39], were p-coumaric acid, gallic acid, and ferulic acid derivatives. Protocatechuic acid, hydroxybenzoic acid, vanillic acid, gallic acid, isovanillic acid, chlorogenic acid, ferulic acid, isoferulic 
acid, syringic acid, caffeic acid, hydroxycinnamic acid, and chlorogenic acid as the main phenolic compounds [40].

Table 1. Preliminary screening of Ajwa fruit pulp and seed extract.

\begin{tabular}{ccc}
\hline Preliminary Screening & Ajwa Fruit Pulp & Ajwa Seed \\
\hline Weight of dry powder of rhizome & $100 \mathrm{~g}$ & $100 \mathrm{~g}$ \\
\hline Yield & $18.79 \%$ & $21.19 \%$ \\
\hline Extract & Methanol & Methanol \\
\hline Color & Reddish brown & Brown \\
\hline Odour & Sweet & No specific \\
\hline Texture & Sticky & Sticky \\
\hline Flavonoid (alkaline reagent test) & + & + \\
\hline Phenolic compounds (FeCl 3 test) & + & + \\
\hline
\end{tabular}

Table 2. Phytochemical screening of Ajwa fruit pulp and seed extract.

\begin{tabular}{ccc}
\hline Phytochemical Constituents & Fruit Pulp & Seed \\
\hline Alkaloids & + & + \\
\hline Saponins & + & + \\
\hline Tannins & ND & ND \\
\hline Flavonoids & + & + \\
\hline Glycosides & + & + \\
\hline Terpenoids & + & + \\
\hline Phenolic compounds $\left(\mathrm{FeCl}_{3}\right.$ test $)$ & + & + \\
\hline
\end{tabular}

\subsection{Hydrogen Peroxide $\left(\mathrm{H}_{2} \mathrm{O}_{2}\right)$ Radical Scavenging}

Reducing capacity and antioxidant activity are directly correlated to each other. Further, there is a significant correlation between antioxidant activity and TPC, hydrogen peroxide scavenging capacity, and DPPH radical scavenging activities. Thus, the assessment of hydrogen peroxide scavenging capacity may be an important indicator to determine the antioxidant activity. The percentage $\mathrm{H}_{2} \mathrm{O}_{2}$ scavenging ability of Ajwa fruit pulp (blue curve) and seed (yellow curve) extracts has been presented in Figure 2. In both cases, $\mathrm{H}_{2} \mathrm{O}_{2}$ scavenging activity was found to be increased in with increase in the concentration of extracts.

\subsection{DPPH Radical Scavenging Assay}

It has been found to be a very high correlation between the concentration of the extracts of natural products and percentage of DPPH radical scavenging activity (Anwar et al., 2020a). In our study, methanol extracts of Ajwa fruit pulp and seed has showed a concentration dependent DPPH scavenging activity (Figure 3) due to their strong antioxidant nature that was comparable to ascorbic acid. $\mathrm{IC}_{50}$ is the concentration of an extract or antioxidant that is essential to decrease DPPH concentration by $50 \%$. The low $\mathrm{EC}_{50}$ value indicates that the antioxidant is more active. The $\mathrm{EC}_{50}$ value of methanol extracts of Ajwa fruit pulp and seed was $1580.360 \pm 0.370$ and $1272.610 \pm 0.270 \mu \mathrm{g} / \mathrm{mL}$ by plot between concentration of methanol extracts and percent of free radical scavenging activity, separately and intercept $=2.710$ and 2.320 . The equations were for both curve $y=0.18460 x+2.710$, and $y=0.1357+2.32$ (in both cases, $R^{2}>0.96$ ). Figure 3 compares the percentage of free radical scavenging potential of fruit pulp (blue) and seed (yellow) in a bar plot. 


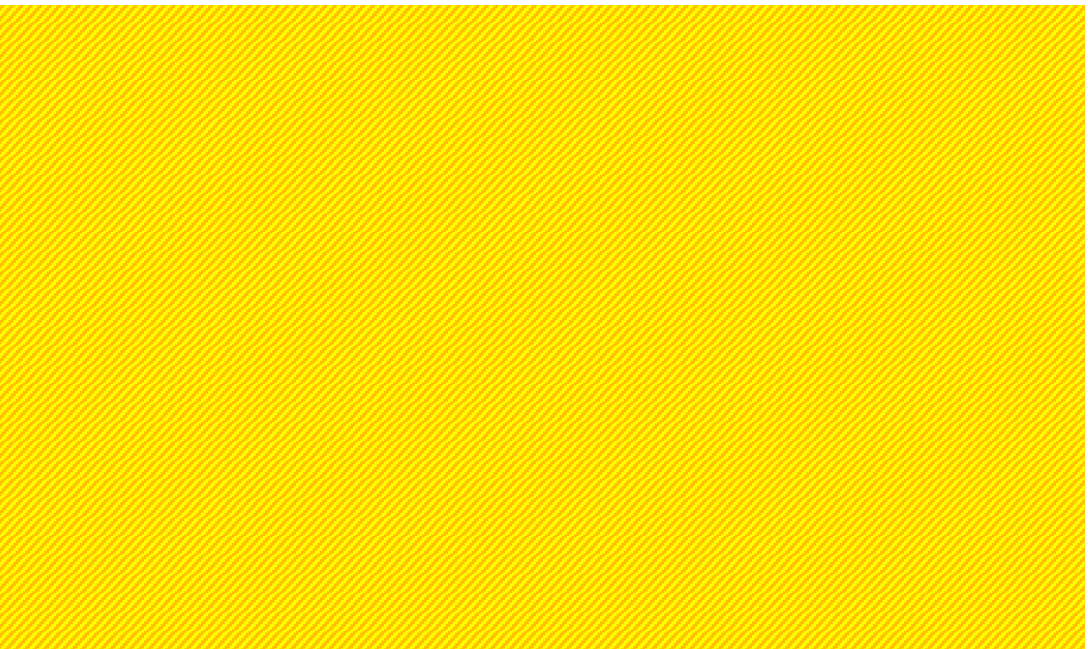

Figure 2. Percentage of $\mathrm{H}_{2} \mathrm{O}_{2}$ scavenging potential of methanol extracts of Ajwa fruit pulp (blue) and seed (yellow). Samples at y-axis show various concentrations of extracts $(100,200,300,400,500$, and $600 \mu \mathrm{g} / \mathrm{mL})$. The results are presented as means $\pm \operatorname{SEM}(n=3, p<0.05)$.

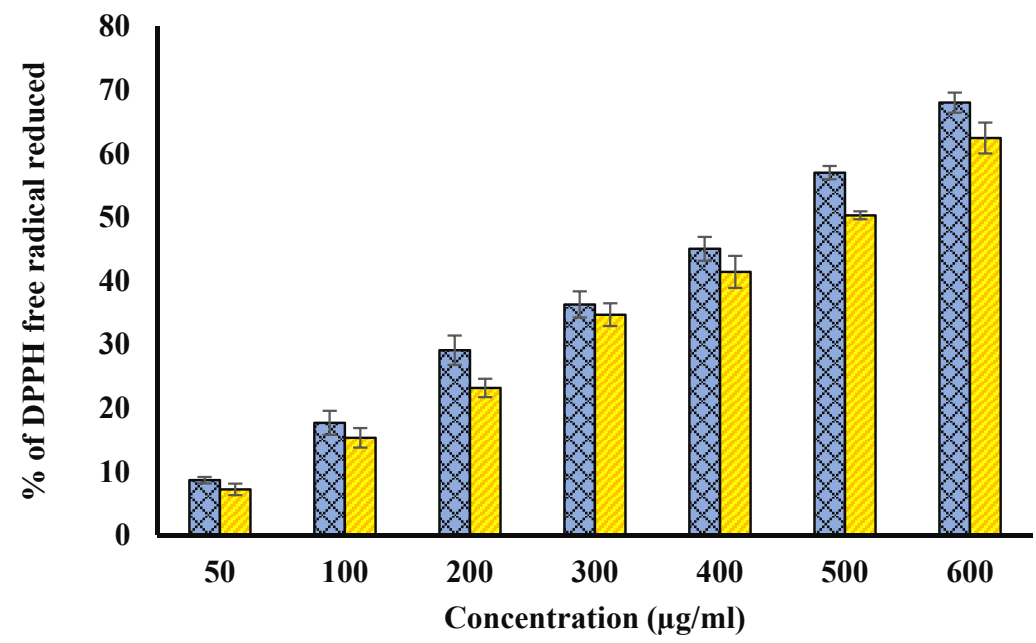

Figure 3. Blue bars show percentage of free radical reduced against fruit pulp concentration $(\mu \mathrm{g} / \mathrm{mL})$. However, yellow columns show the percentage free radical scavenging activity against seed extract concentration $(\mu \mathrm{g} / \mathrm{mL})$ of. The $p$-value significance was found to be less than 0.05 for this figure $(p<0.05)$.

\subsection{Determination of Protein Denaturation inhibition}

During the denaturation process, many weak bonds including hydrogen bonds responsible for native structure of protein become broken. Thus, highly ordered structure of protein become lost. Various factors such as chemicals or stress induce protein denaturation. Besides, protein denaturation contributed to inflammation significantly. As a result, the plausible anti-inflammatory potential of fruit pulp and seed was evaluated by protection from BSA denaturation. The extracts of both pulp and seed were found to be very effective against heat-induced BSA denaturation (Figure 4). Ibuprofen displayed the maximum inhibition, $63.010 \pm 0.48 \%$ at $200 \mu \mathrm{g} / \mathrm{mL}$. 


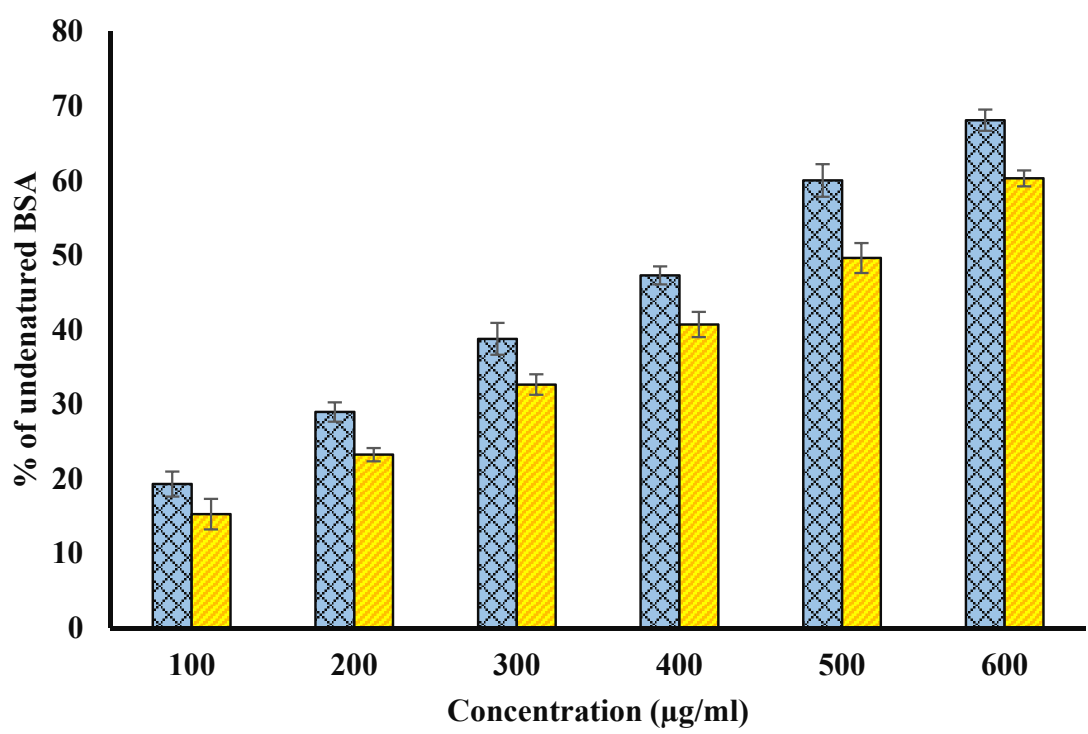

Figure 4. Percentage of undenatured BSA. Blue bars show percentage of undenatured BSA plot for various concentrations $(\mu \mathrm{g} / \mathrm{mL})$ of fruit pulp. However, yellow columns show the percentage of undenatured BSA plot for various concentrations $(\mu \mathrm{g} / \mathrm{mL})$ of seed extract. The $p$-value significance was found to be less than 0.05 for this figure $(p<0.05)$.

\subsection{Anti-Proteinase Activity}

Proteinases are known to be involved in arthritic reactions. Both extracts inhibited proteinase activity, and Ajwa fruit pulp and seed methanol extracts $(600 \mu \mathrm{g} / \mathrm{mL})$ showed the highest proteinase inhibition potential of 68 and $60 \%$, respectively, in this study (Figure 5). Diclofenac sodium showed maximum anti-proteinase activity, i.e., $71.59 \pm 0.075$ at $200 \mu \mathrm{g} / \mathrm{mL}$.

\subsection{Inhibition of Egg Albumin Denaturation Inhibition}

The possible anti-arthritic potential of both extracts was evaluated using inhibition of the denaturation of hen egg albumin (Figure 6). The significant ability to protect from heat- induced hen egg albumin denaturation might be due to various non-enzymatic antioxidants such as polyphenols. Diclofenac protected from denaturation by $67.010 \pm 0.78 \%$, at $200 \mu \mathrm{g} / \mathrm{mL}$.

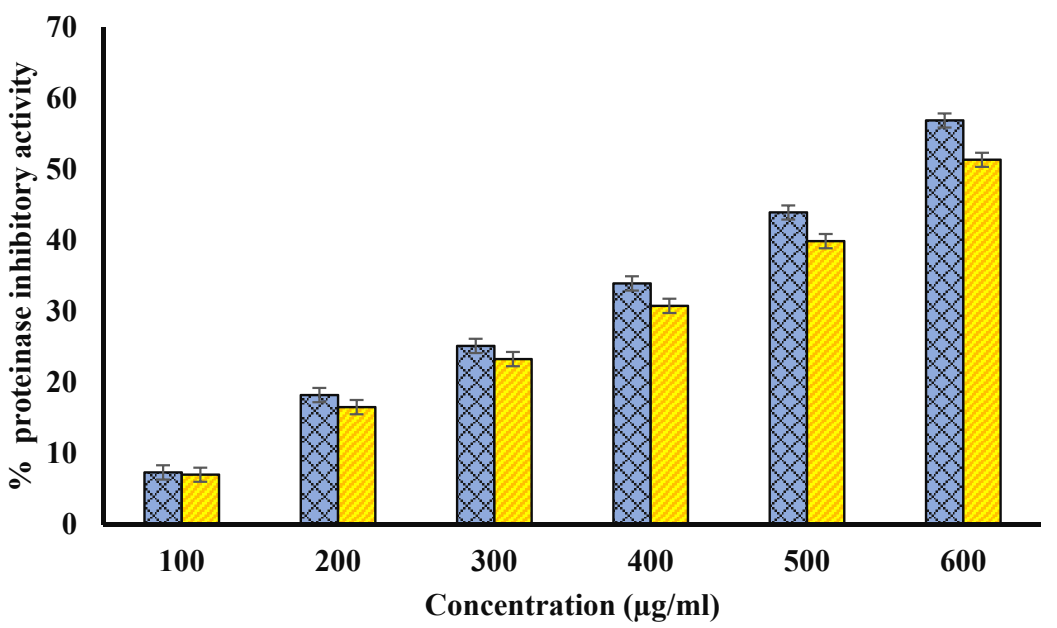

Figure 5. Percentage of proteinase inhibitory activity. Blue bars show percentage of proteinase inhibitory activity plot for various concentrations $(\mu \mathrm{g} / \mathrm{mL})$ of fruit pulp. However, yellow columns show the percentage of proteinase inhibitory activity plot for various concentrations $(\mu \mathrm{g} / \mathrm{mL})$ of seed extract. The $p$-value significance was found to be less than 0.05 for this figure $(p<0.05)$. 


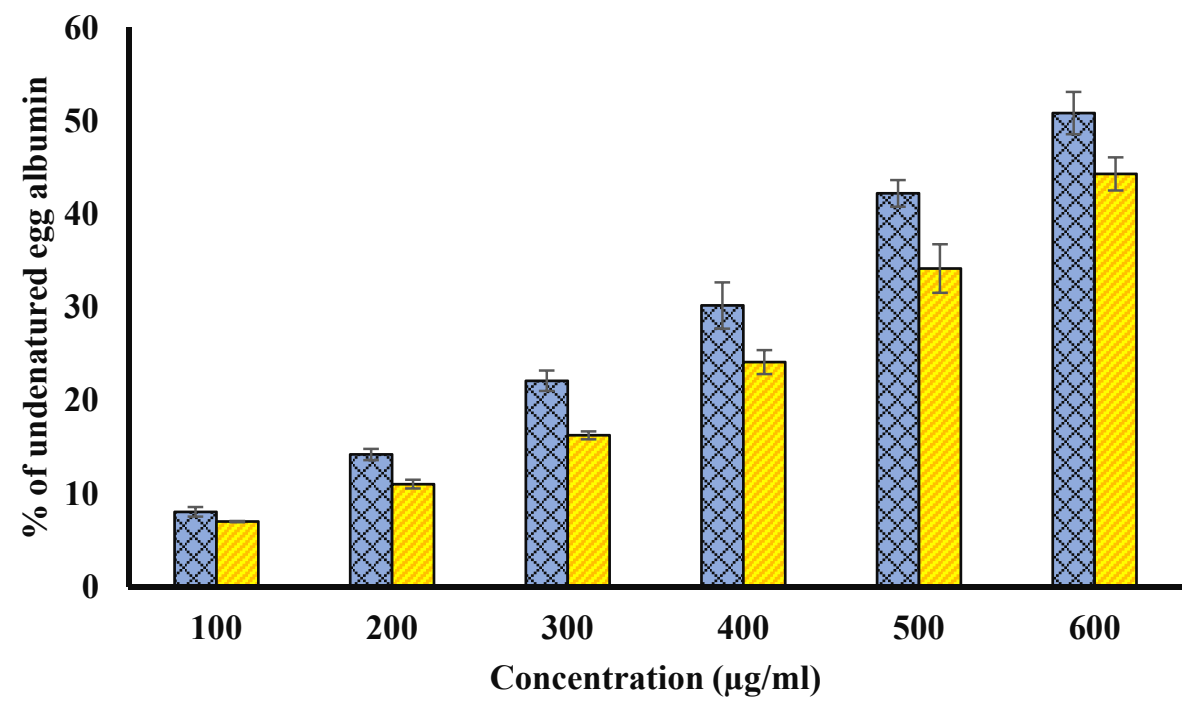

Figure 6. Percentage of undenatured egg albumin. Blue bars show percentage of undenatured egg albumin plot for various concentrations $(\mu \mathrm{g} / \mathrm{mL})$ of fruit pulp. However, yellow columns show the percentage of undenatured egg albumin plot for various concentrations $(\mu \mathrm{g} / \mathrm{mL})$ of seed extract. The $p$-value significance was found to be less than 0.05 for this figure $(p<0.05)$.

\subsection{Test for Membrane Stabilization Potential}

The test for stabilization of the RBCs membrane was performed to further uncover the possible mechanism of anti-inflammatory activity of seed and fruit pulp.

\subsection{Heat Induced Hemolysis}

Both extracts showed a significant $(p<0.01)$ membrane stabilizing potential against hemolysis at all concentrations (Figure 7). Methanol extracts of fruit pulp and seed had highest stabilization of human RBCs membrane (or highest inhibition of hemolysis) by $54.44 \pm 0.31$ and $50.21 \pm 0.63 \%$ at $600 \mu \mathrm{g} / \mathrm{mL}$, respectively, in the current study that was comparable to standard reference drug, i.e., aspirin. Aspirin showed the highest protection from hemolysis by $73.64 \pm 0.117 \%$ at $200 \mu \mathrm{g} / \mathrm{mL}$.

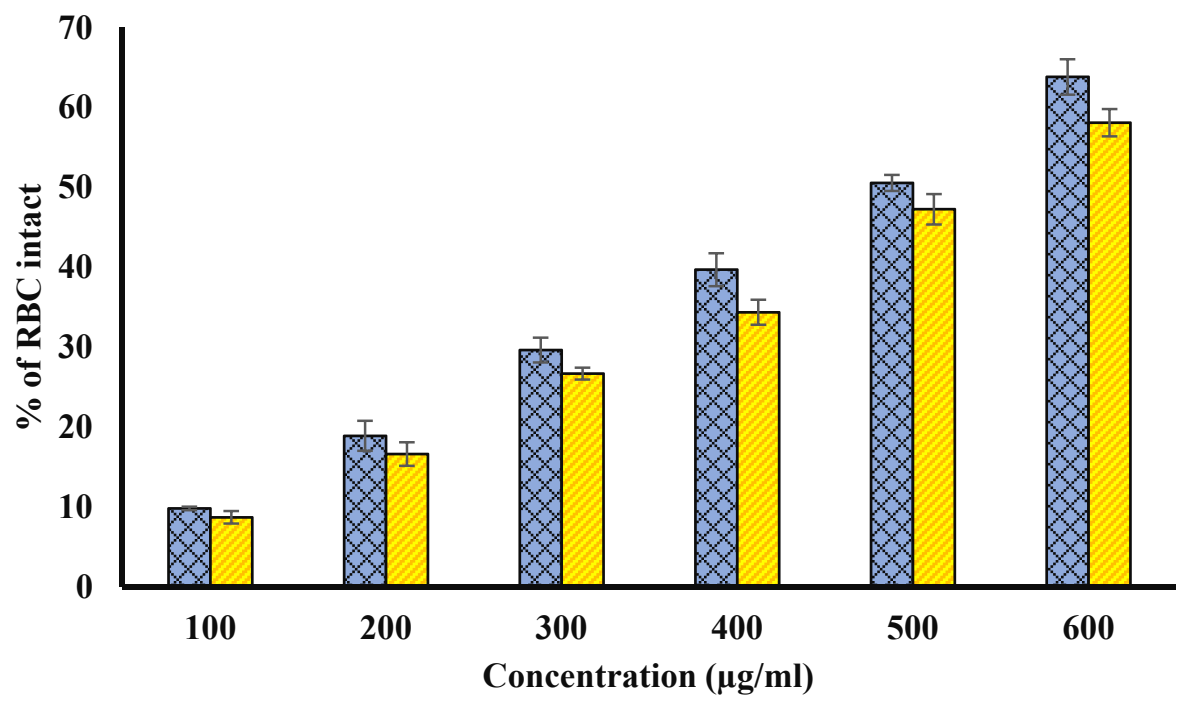

Figure 7. Percentage of RBC intact. Blue columns represent various concentrations $(100-600 \mu \mathrm{g} / \mathrm{mL})$ of Ajwa fruit pulp. Yellow columns represent various concentrations (100-600 $\mu \mathrm{g} / \mathrm{mL}$ ) of Ajwa seed extract. The results are presented as means $\pm \operatorname{SEM}(n=3, p<0.05)$. 


\subsection{Protection from Hypotonicity Induced Hemolysis}

Extract of Ajwa fruit pulp and seed showed a very good protection for hyposalineinduced hemolysis. Hypotonicity induces hemolysis and contributes to the osmotic loss occurs. In our study, in vitro membrane stabilization was shown by both methanol extracts of Ajwa fruit pulp and seed. Hypotonicity-induced hemolysis was inhibited by both extracts. The percentage inhibition of hemolysis in normal adult erythrocytes by the extract was found to be increased with increase in the concentrations (Figure 8). The standard drug diclofenac sodium with percentage inhibition of $69.34 \%$ (at $200 \mu \mathrm{g} / \mathrm{mL}$ ) had higher efficacy in inhibiting hypotonic-induced hemolysis of normal erythrocytes.

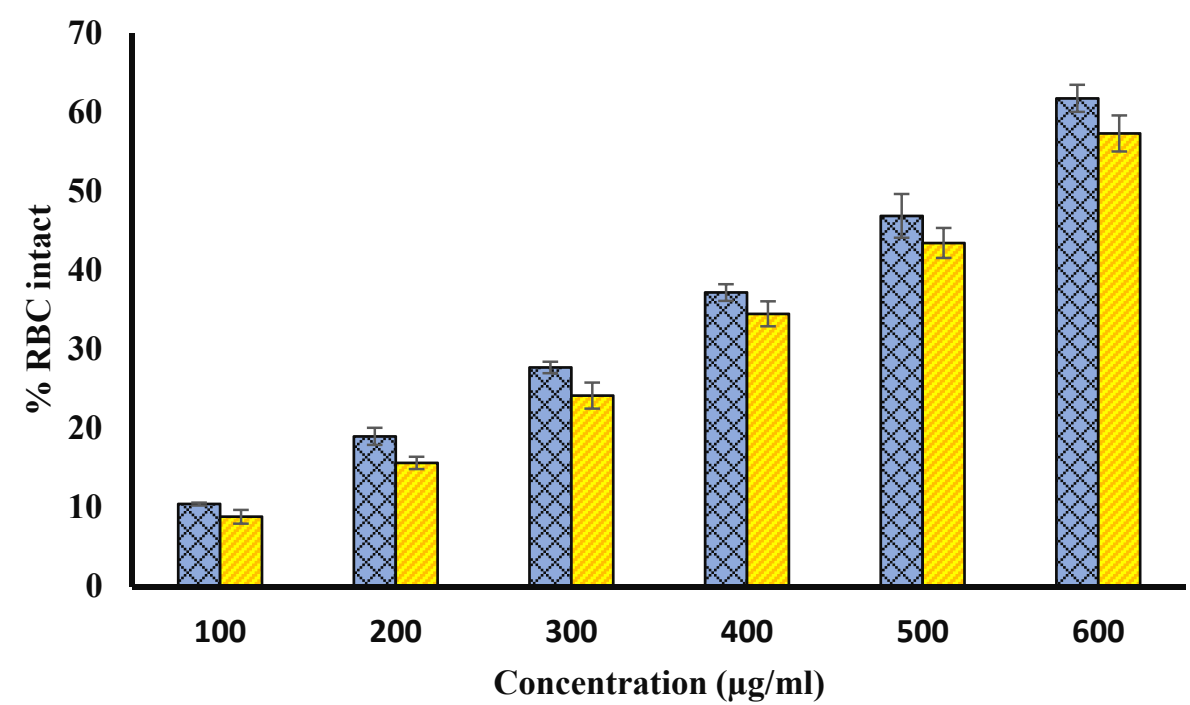

Figure 8. Protection from hyposalinity-induced hemolysis. The figure shows that methanol extract of Ajwa seed and fruit pulp provide protection for hyposalinity-induced hemolysis in a concentrationdependent manner. Blue bars show various concentrations $(100,200,300,400,500$, and $600 \mu \mathrm{g} / \mathrm{mL})$ of Ajwa fruit pulp. Yellow columns represent various concentrations (100, 200, 300, 400, 500, and $600 \mu \mathrm{g} / \mathrm{mL})$ of seed extract. The results are presented as means $\pm \operatorname{SEM}(n=3, p<0.05)$.

\subsection{Effect of Extract on Browning Intensity of Glycated Samples}

BSA was glycated by incubating for 15 days at $37^{\circ} \mathrm{C}$ with glucose in the absence or presence of seed methanol extract. In our experiment, methanol seed extract was found to have the significant potential to inhibit browning (hence, glycation). The methanol extract of seed exhibited $63.29 \%$ browning (at $600 \mu \mathrm{g} / \mathrm{mL}$ ) as compared to glycated BSA (BSA incubated with glucose only). The browning intensity of glycated BSA (BSA incubated with glucose only) was supposed to have $100 \%$ browning (Figure 9). Our results indicate the presence of extract lead to lesser glycation (or lesser brown products). Hence, browning becomes inhibited in the presence of extracts.

\subsection{Effect of Seed Extract on Protein Aggregation Index}

Glycation occurs at N-terminal group or at the side chains of a polypeptide, and it contributes significantly in the modification of protein structure and functions. Further, glycation leads to the formation of aggregates of protein because carbonyl groups linked with protein induce the formation of cluster. There are various reports regarding the involvement of protein aggregates in various diseases and their complications. Many natural products have been reported to protect against aggregate formation in glycated proteins [10-14]. Glycated BSA samples incubated with Ajwa seed extract showed a lesser aggregation index as compared to glycated BSA (Figure 10). 


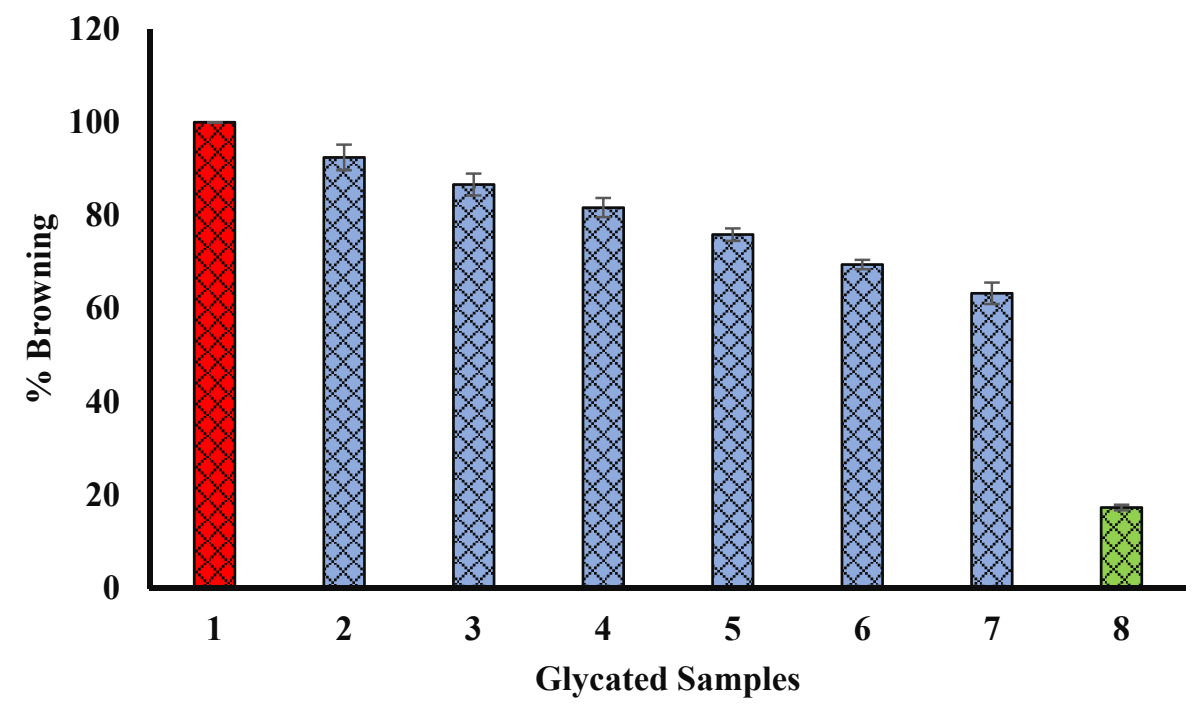

Figure 9. Reduction in \% of browning by seed extract. Sample 1 (red column) belongs to BSA kept with glucose for 15 days (100\% glycation or browning). Bars 2, 3, 4, 5, 6, and 7 show $\%$ of browning of glycated samples with 100, 200, 300, 400, 500, and $600 \mu \mathrm{g} / \mathrm{mL}$ of Ajwa seed extract (blue columns) and $\%$ of browning (the degree of glycation) was found to be decreased with an increase in the concentration of seed extract. Bar 8 (green column) shows the $\%$ of browning of BSA incubated in the absence of any extract or glucose, and exhibited the least browning (glycation). The results are presented as means $\pm \operatorname{SEM}(n=3, p<0.05)$.

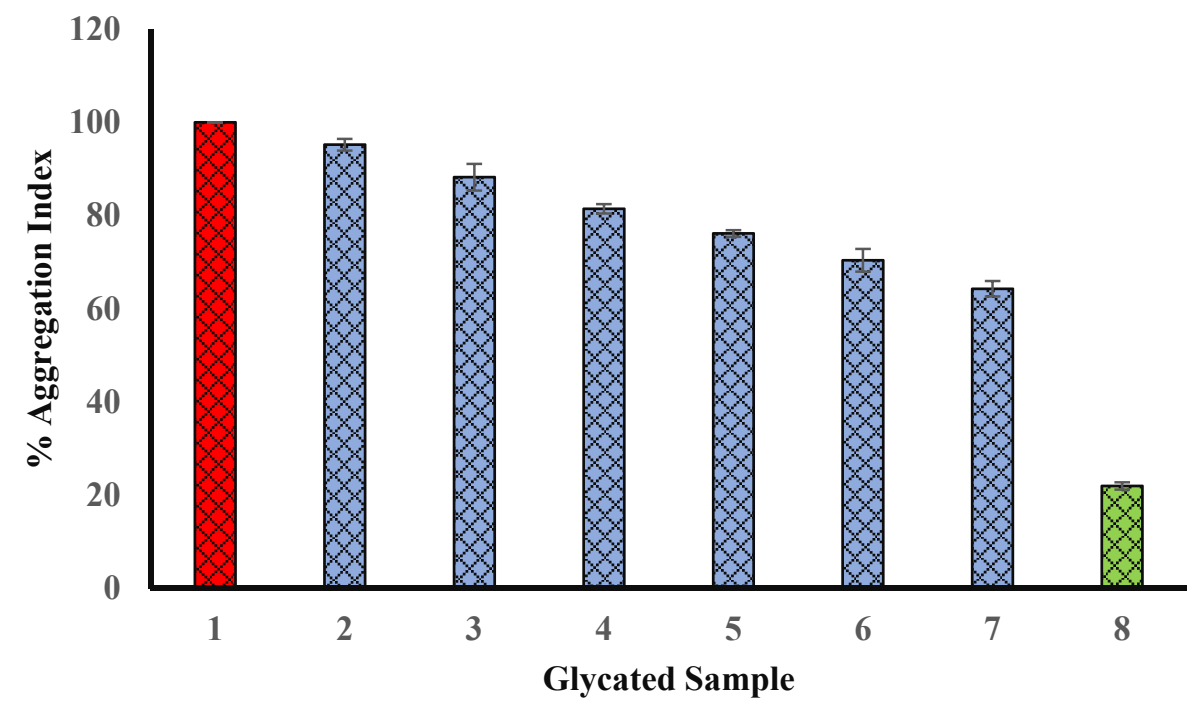

Figure 10. Reduction in percent of aggregation in presence of Ajwa seed methanol extract. Sample 1 (red column) belongs to BSA kept with glucose for 15 days (100\% aggregation). Bars 2, 3, 4, 5, 6, and 7 show percent of aggregation of glycated samples with 100, 200, 300, 400,500, and $600 \mu \mathrm{g} / \mathrm{mL}$ of Ajwa seed extract (blue columns), and the percent of aggregation (the degree of glycation) was found to be decreased with an increase in the concentration of seed extract. Bar 8 (green column) shows the percent aggregation of BSA incubated in the absence of any extract or glucose, and exhibited the least aggregation (glycation). The results are presented as means $\pm \operatorname{SEM}(n=3, p<0.05)$.

\subsection{Congo Red (CR) Assay}

The amyloidogenic dye Congo red (CR) effectively interacts with amyloid fibrils and is used to stain amyloid fibrils. Congo red binds to amyloid fibrils of proteins due to several mechanisms including electrostatic interaction with surface residues (positively charged) of the fibril. In aqueous solution, the absorption spectrum of CR shows the highest absorption 
at $490 \mathrm{~nm}$ (blue/green), resulting in a red color solution, at a low concentration and neutral $\mathrm{pH}$. The binding of $\beta$-sheet-rich amyloid fibrils to $\mathrm{CR}$ is linked with specific orientation of CR dye molecules (i.e., with the long axis of the CR molecules lying parallel to the fibril axis). It causes a red shift (from 490 to $540 \mathrm{~nm}$ ) in the absorption maximum. In our experiment, the binding of CR was investigated by recording the absorbance of CR-bound glycated samples at $540 \mathrm{~nm}$. The data of the CR binding assay experiment are shown in the Figure 11. Glycated samples with various concentrations of Ajwa seed extract (blue column) indicated a decrease in the fibrillation of BSA.

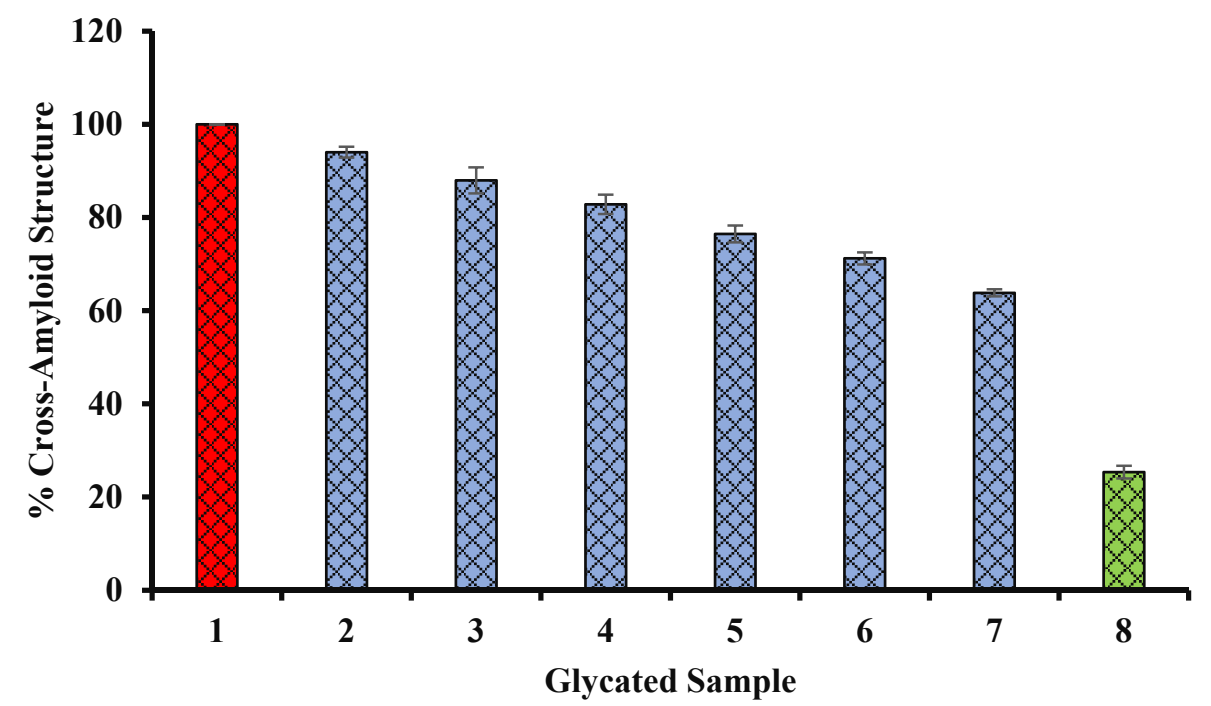

Figure 11. Decrease in cross amyloid structures in the presence of Ajwa seed extract (blue column). Sample 1 (red column) belongs to BSA kept with glucose for 15 days (100\% structural modifications). Bars 2, 3, 4, 5, 6, and 7 show percent of structural modifications of glycated samples with 100, 200, $300,400,500$, and $600 \mu \mathrm{g} / \mathrm{mL}$ of Ajwa seed extract (blue columns), and structural modifications were found to be decreased with an increase in the concentration of seed extract. Bar 8 (green column) shows the structural modifications of BSA incubated in the absence of any extract or glucose, and exhibited the least structural modifications (glycation). The results are presented as means \pm SEM $(n=3, p<0.05)$.

\subsection{Antimicrobial Activity of Seed and Fruit Pulp Extract}

Several studies have documented the positive correlation between antioxidant activities of date fruits and antibacterial activities, and they have been shown against common bacterial food pathogens and important disease pathogens. In our experiment, we tested the antimicrobial activity of date fruit pulp extract as well as seed extract of both Gramnegative bacteria and Gram-positive bacteria. The methanol seed extract exhibited the highest inhibitory zone against all tested bacterial strains. However, the fruit pulp did not show a notable inhibitory zone to these bacterial strains and Candida. Seed extract showed notable antimicrobial activity at $100 \mathrm{mg} / \mathrm{mL}$. The inhibition induced by a plant extract against a particular organism was determined by several factors including both external as well as internal factors. The diameter of the zone of inhibition by extract of Ajwa seed against different organisms is shown in Table 3. MIC values are provided in Table 4. 
Table 3. Zone of inhibition against different bacterial strains in the presence of seed extract.

\begin{tabular}{ccc}
\hline \multirow{2}{*}{ Test Organisms } & \multicolumn{3}{c}{$\begin{array}{c}\text { Seed Extract } \\
\text { (The Diameter of the Zone of Inhibition in } \mathbf{~ m m} \text { ) }\end{array}$} \\
\cline { 2 - 3 } & For $\mathbf{5 0} \mathbf{~} \mathbf{g} / \mathbf{m L}$ & For $\mathbf{1 0 0} \mathbf{~} \mathbf{g} \mathbf{m L}$ \\
\hline S. aureus & 13 & 19 \\
\hline E. coli & 10 & 15 \\
\hline K. pneumoniae & 12 & 16 \\
\hline P. aeruginosa & 9 & 14 \\
\hline E. faecalis & 11 & 16 \\
\hline
\end{tabular}

Table 4. MIC value against of seed extract different bacterial strains.

\begin{tabular}{cc}
\hline Test Organisms & $\begin{array}{c}\text { MIC Value of Seed Extract } \\
(\mathbf{m g} / \mathbf{m L})\end{array}$ \\
\hline S. aureus & 25 \\
\hline E. coli & 25 \\
\hline K. pneumoniae & 25 \\
\hline P. aeruginosa & 50 \\
\hline E. faecalis & 25 \\
\hline
\end{tabular}

\subsection{Receptor-Ligand Interaction Study by Molecular Docking}

In molecular docking studies, we studied the molecular interaction of necessary antioxidant enzymes, superoxide dismutase (SOD 1 complexed with isoproterenol (PDB id: 5YTU) and catalase catalase3-amino-1,2,4-triazole complex (PDB id: 1DGH)) with the different active constituents of Ajwa date fruit, including 3,3'-Di-O-methylellagic acid, 7-methoxyquercetin-O-hexose isomers or rhamnetin, caffeic acid, ferulic acid, quercetinrutinoside, $6^{\prime \prime \prime}$-malonylicariin or kaempferol methyl ether, 4-hydroxybenzoic acid, phytol, punicalagin, and quercetin-3-O-glucoside or isoquercitrin.

Based on the results, all the ligands considered for docking analysis of the Ajwa date can bind with both enzymes superoxide dismutase (5YTU) and catalase (1DGH), except ligand punicalagin (Figure 12g). The ligand punicalagin showed binding energy of $19.7 \mathrm{kcal} / \mathrm{mol}$ with 1DGH. Details of molecular dockings analysis, such as the name of ligands, PubChem CIDs, binding energy, and interacting amino acids interacting with receptors 1DGH and 5YTU, are shown in Table 5. Figure 12 shows molecular interactions of antioxidant enzymes 1DGH and 5YTU with ligands (active molecules) of the Ajwa date. The primary functional residues in the interactions with 1DGH are amino acids Arg72, Ala357, and Leu144, while with 5YTU, the amino acids are Gly37, Pro13, and Asp11. The A-chain of enzymes is also observed with the interacting amino acids, which is denoted with the " $\mathrm{A}$ " with the interacting amino acids. The different types of interactions of the ligand and interacting amino acid of the receptor molecules are shown with different colors; such as the conventional hydrogen bond (dark green), carbon-hydrogen bond (green), Pi-hydrogen bond (light green), Pi-lone pair (faint green), Pi-cation (orange), Pi-Pi (pink), Pi-alkyl (light pink), Pi-Sigma (purple), and unfavorable acceptor-acceptor bump (red) (Figure 12).

The Ramachandran plot shows the statistical distribution of the combinations of the backbone dihedral angles Phi $(\phi)$ and Psi $(\psi)$. In practice, the distribution of the $\mathrm{Phi} /$ Psi values observed in a protein structure can be used for structure validation. The Ramachandran plot visualizes energetically allowed and forbidden regions for the dihedral angles [41]. The Ramachandran plot analysis of both the enzymes with Ajwa date ligands suggests that most residues are in favored areas $(B, D, F, H, J, L, N, P, R, T, V, X, Z, b, d, f, h$, $\mathrm{j}, \mathrm{i}$, and $\mathrm{n})$. 
Table 5. Details of molecular docking study; the ligands, binding energy, and interacting amino acids interacting with receptors (1DGH and 5YTU).

\begin{tabular}{|c|c|c|c|c|c|}
\hline \multicolumn{2}{|l|}{ Enzymes } & \multicolumn{2}{|c|}{ Catalase (1DGH) } & \multicolumn{2}{|c|}{ Superoxide Dismutase (5YTU) } \\
\hline Ligands & PubChem CID & $\begin{array}{l}\text { Binding Energy } \\
(\mathrm{kcal} / \mathrm{mol})\end{array}$ & Interacting Amino Acids & $\begin{array}{l}\text { Binding Energy } \\
(\mathbf{k c a l} / \mathrm{mol})\end{array}$ & Interacting Amino Acids \\
\hline $\begin{array}{l}\text { 3,3'-Di-O-methyl } \\
\text { ellagic acid }\end{array}$ & 5488919 & -9.9 & $\begin{array}{c}\text { Arg72, Arg112, Asn148, } \\
\text { Gly131, His75, Tyr358, Val73, } \\
\text { Val74, Val146, Ala133 }\end{array}$ & -5.1 & Arg143, leu144, Pro13 \\
\hline Rhamnetin & 5281691 & -10.4 & $\begin{array}{c}\text { Phe132, Arg112, Arg365, } \\
\text { Val73, Val146, His75, Tyr358, } \\
\text { Ala133, Arg72 }\end{array}$ & -5.8 & $\begin{array}{l}\text { Asp11, Thr39, Gly37, Arg143, } \\
\text { Leu144, Pro13 }\end{array}$ \\
\hline Caffeic acid & 689043 & -7.3 & $\begin{array}{l}\text { His362, Ser114, Arg365, } \\
\text { Arg72 }\end{array}$ & -5.0 & Thr39, Gly37, Leu144 \\
\hline Ferulic acid & 445858 & -7.4 & $\begin{array}{c}\text { Arg365, Ile332, Arg72, Phe334, } \\
\text { His362 }\end{array}$ & -4.6 & $\begin{array}{l}\text { Gly37, Thr39, Gly12, Asp11, } \\
\text { Leu144, Pro13, Val14 }\end{array}$ \\
\hline $\begin{array}{l}\text { Quercetin } \\
\text { rutinoside }\end{array}$ & 124221768 & -4.7 & $\begin{array}{l}\text { His166, Thr361, Ala357, Val73, } \\
\text { Ile165 }\end{array}$ & -6.1 & Gly37, Pro13, Leu144 \\
\hline $\begin{array}{c}6^{\prime \prime \prime}- \\
\text { Malonylicariin }\end{array}$ & 135398032 & -8.5 & $\begin{array}{c}\text { Asn148, Tyr358, Asp360, } \\
\text { Ala357, Phe161, Pro158, } \\
\text { Phe356, Pro162 }\end{array}$ & -5.7 & $\begin{array}{c}\text { Asp11, Gly12, Leu38, Gly37, } \\
\text { Pro13 }\end{array}$ \\
\hline $\begin{array}{l}\text { 4-Hydroxy } \\
\text { benzoic acid }\end{array}$ & 135 & -6.5 & $\begin{array}{c}\text { His75, Phe334, Arg72, Arg365, } \\
\text { Ala133 }\end{array}$ & -4.0 & Leu144, Pro13, Asp11 \\
\hline Phytol & 5280435 & -8.2 & $\begin{array}{c}\text { His218, Ser217, Tyr358, } \\
\text { Met350, Phe153, Pro158, } \\
\text { Ala357, Phe161, Arg354, } \\
\text { Val74, Arg72 }\end{array}$ & -4.1 & Asp11, His43, Pro13, Leu144 \\
\hline Punicalagin & 44584733 & 19.7 & $\begin{array}{l}\text { His364, Asp360, Met350, } \\
\text { Pro162, Ala357, Arg354, } \\
\text { Val74, Ala133, Val146 }\end{array}$ & -5.6 & Leu38, Lys36, Gly37 \\
\hline Isoquercitrin & 5280804 & -8.6 & $\begin{array}{l}\text { Ala357, His75, Phe161, } \\
\text { Arg354, Val74 }\end{array}$ & -5.4 & Gly37, Leu144, Asp11 \\
\hline
\end{tabular}

A

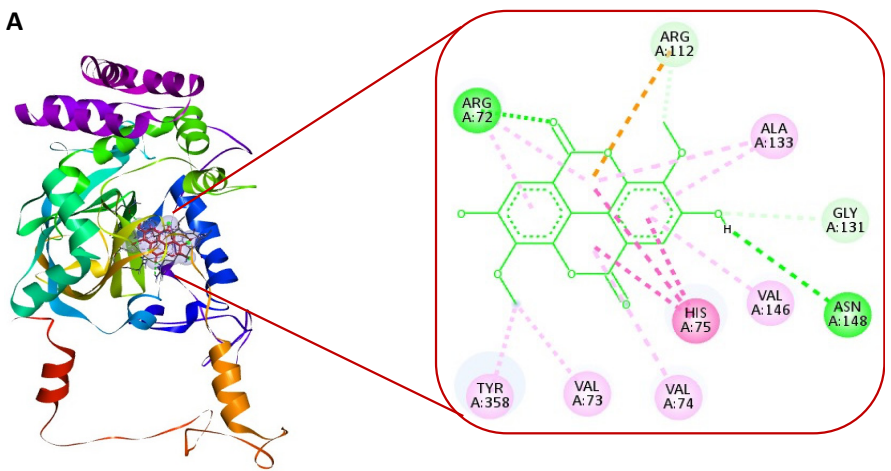

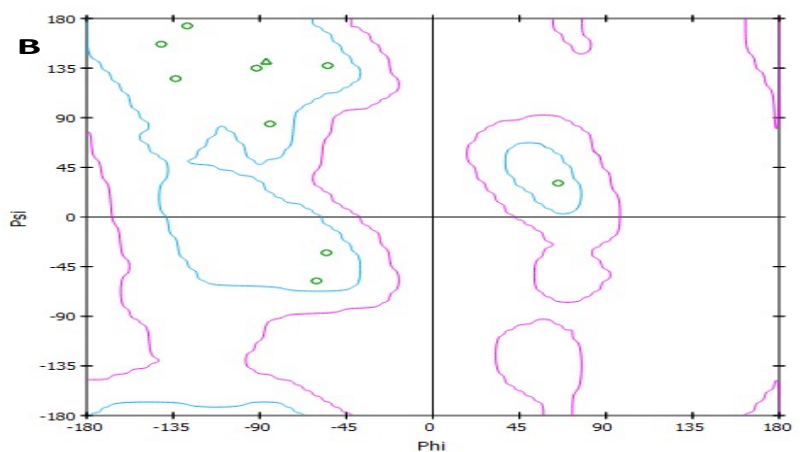

(1a) 1DGH and 3,3'-Di-O-methylellagic acid
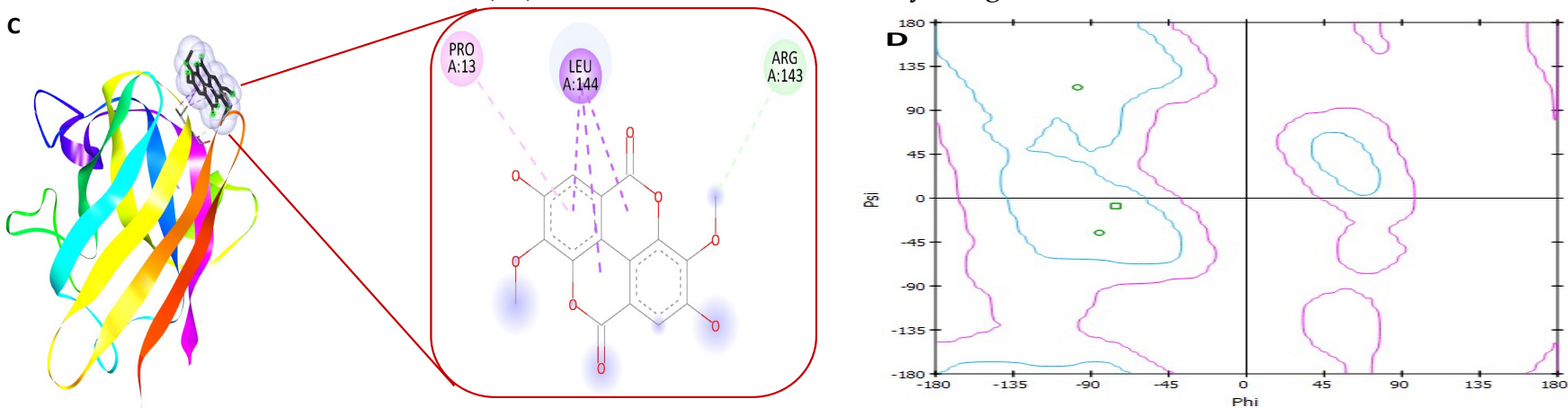

(1b) 5YTU and 3,3'-Di-O-methylellagic acid

Figure 12. Cont. 

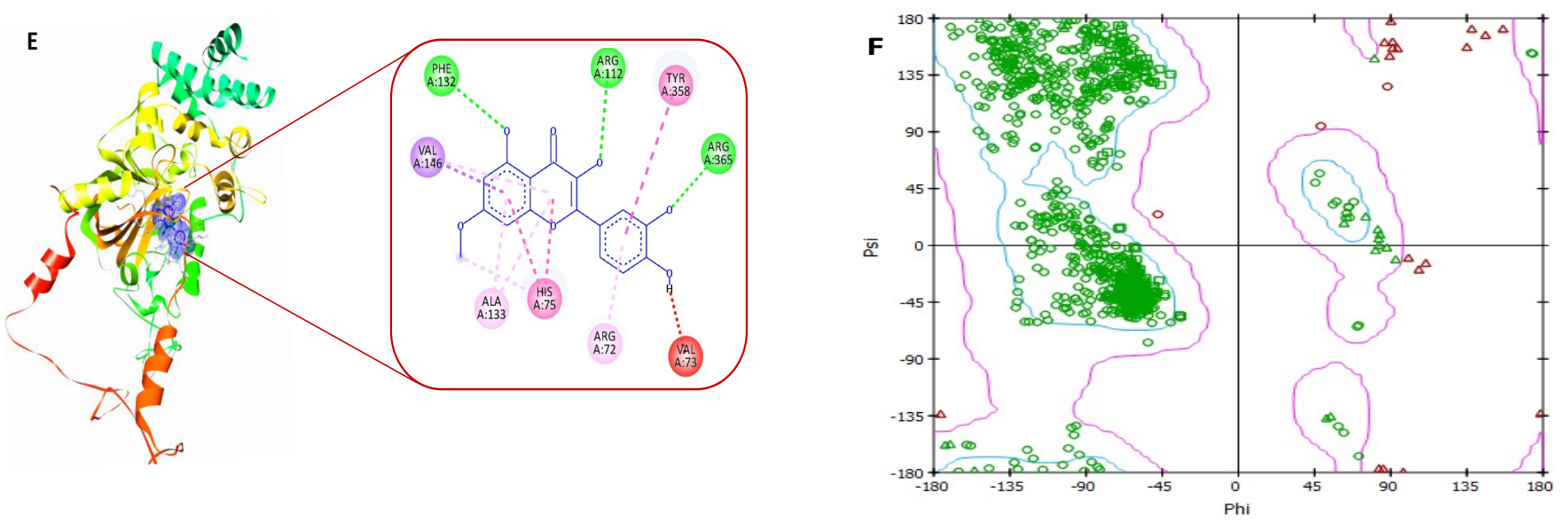

(2a) 1DGH and rhamnetin
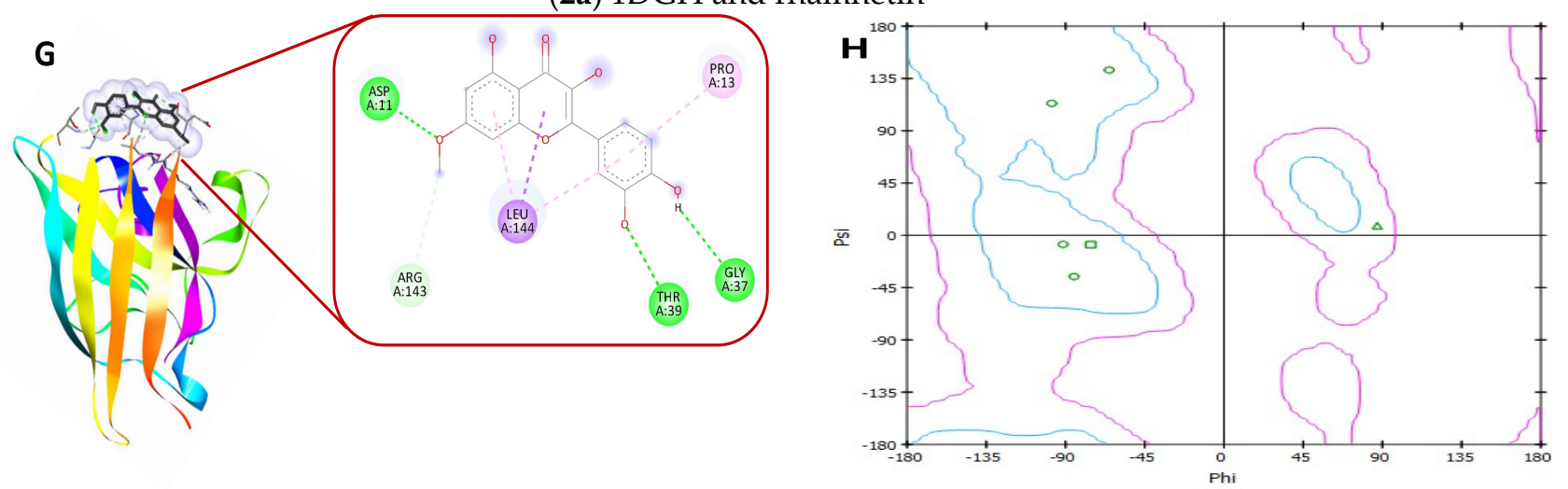

(2b) 5YTU and rhamnetin
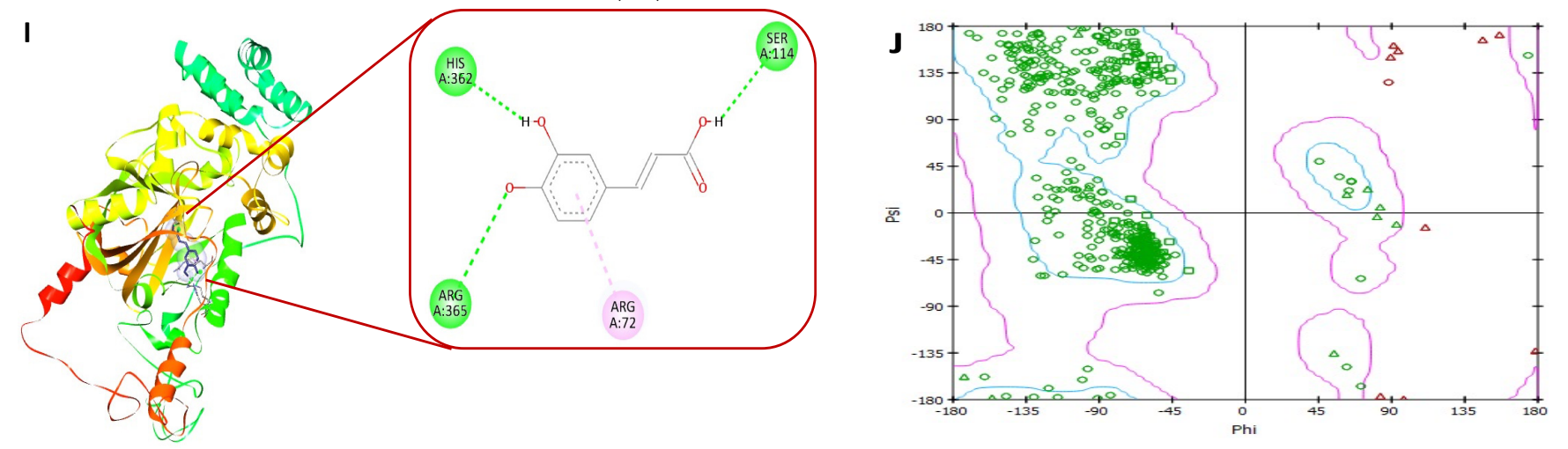

(3a) 1DHG and caffeic acid
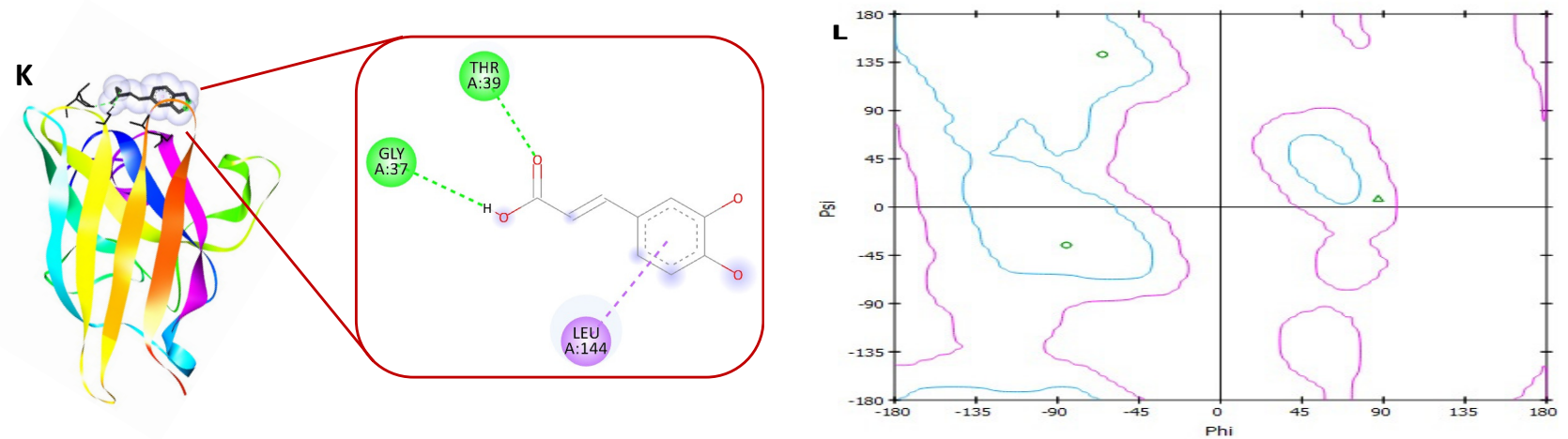

(3b) 5YTU and caffeic acid

Figure 12. Cont. 

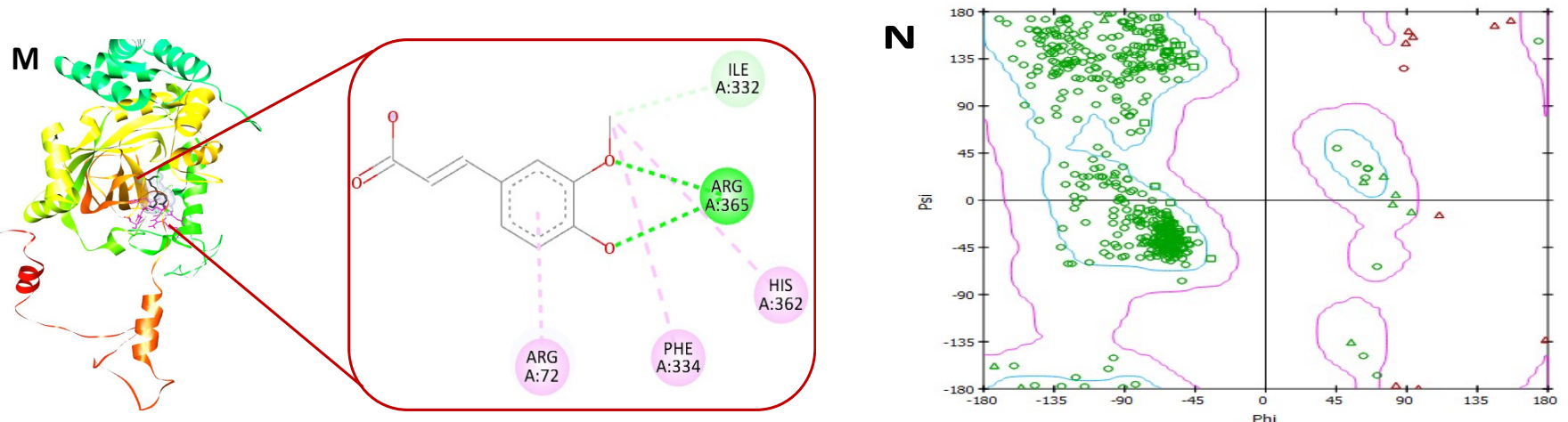

(4a) 1DGH and ferulic acid
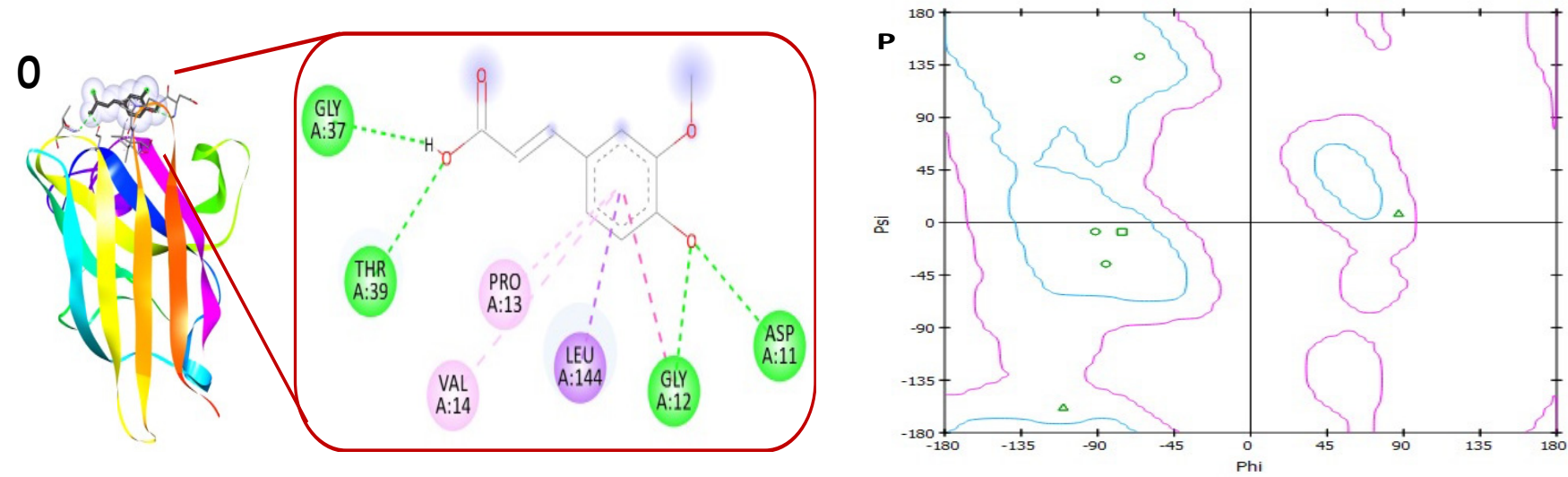

(4b) 5YTU and ferulic acid
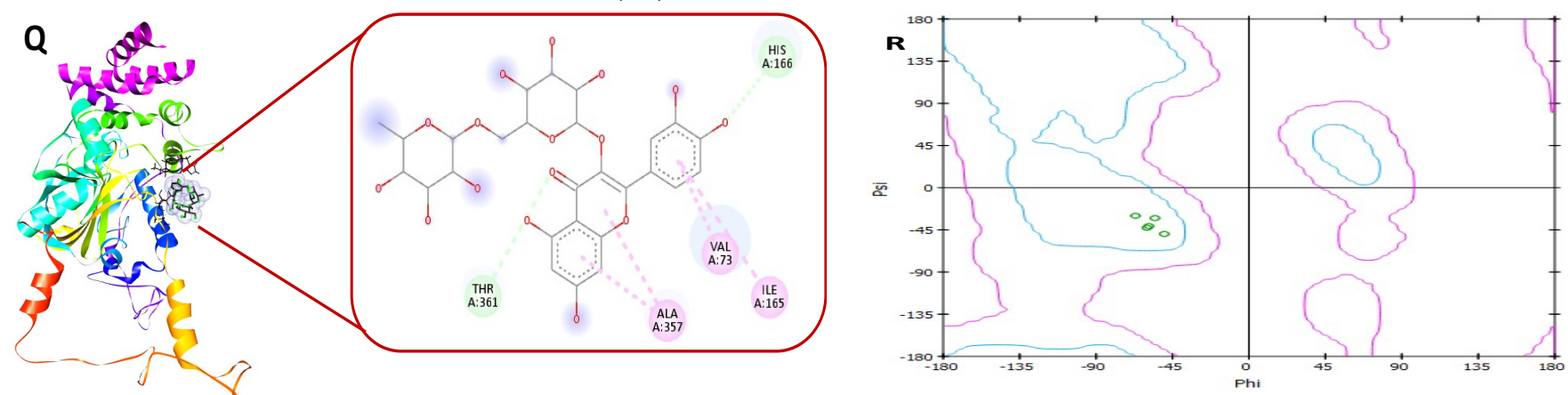

(5a) 1DGH and quercetin rutinoside

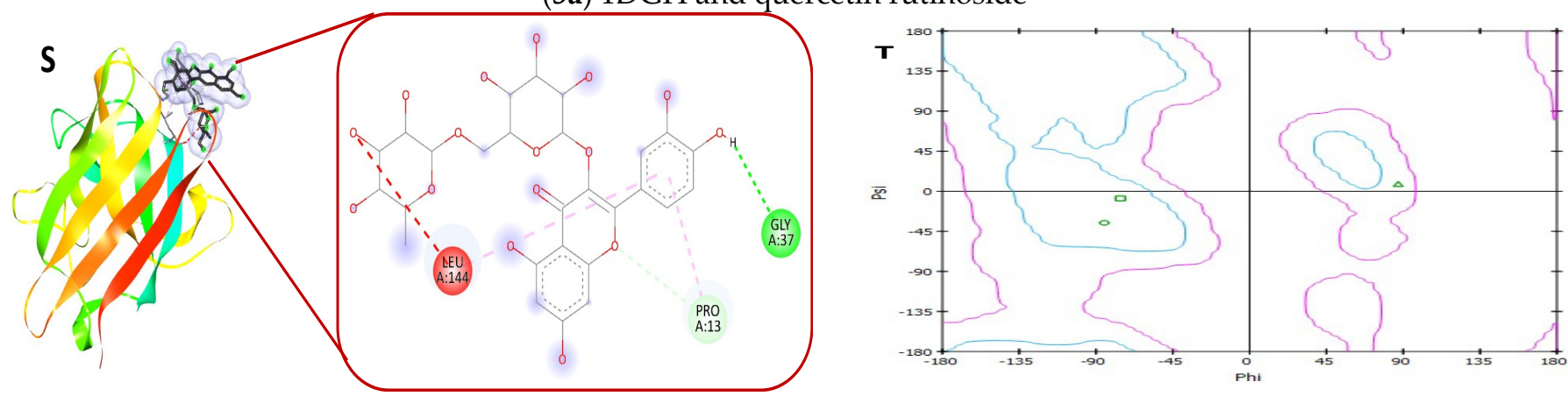

(5b) 5YTU and quercetin rutinoside

Figure 12. Cont. 

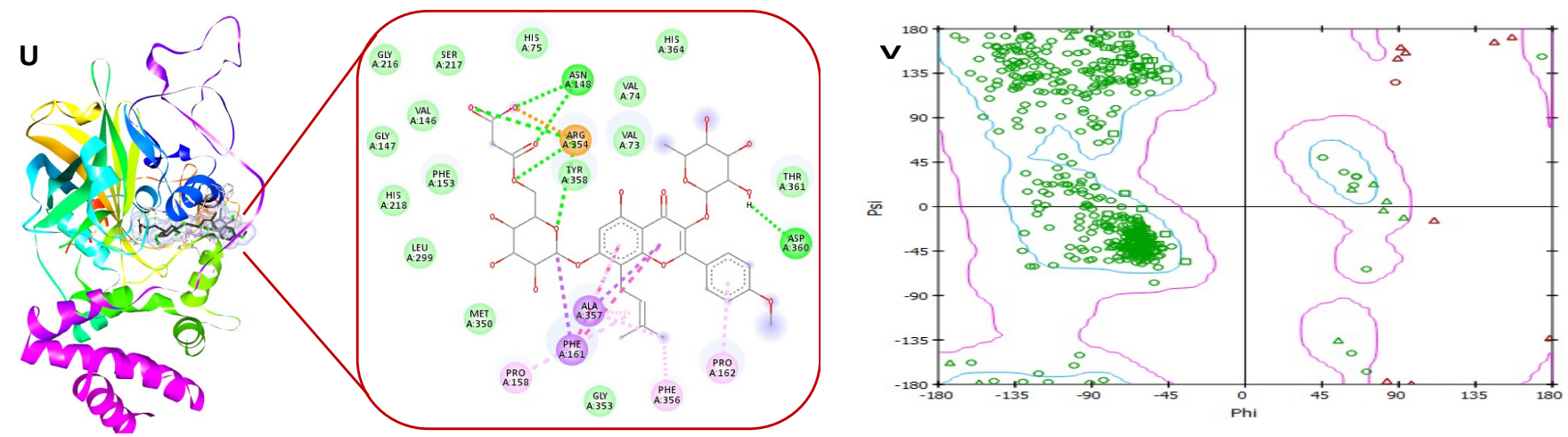

(6a) 1DGH and 6"'malonylicariin
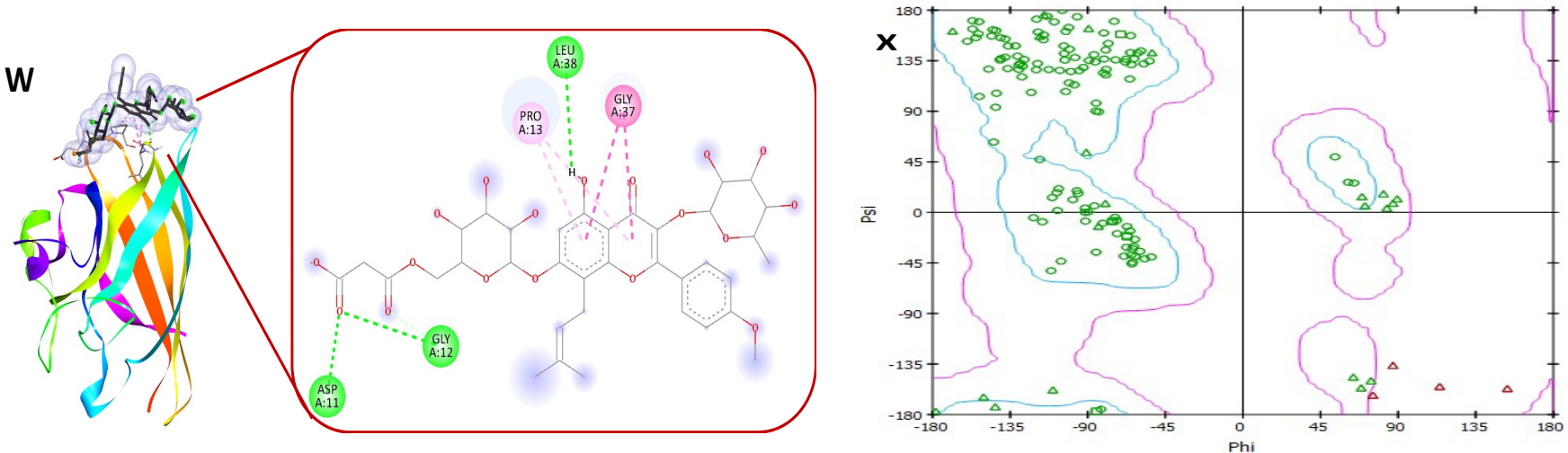

(6b) 5YTU and 6"malonylicariin
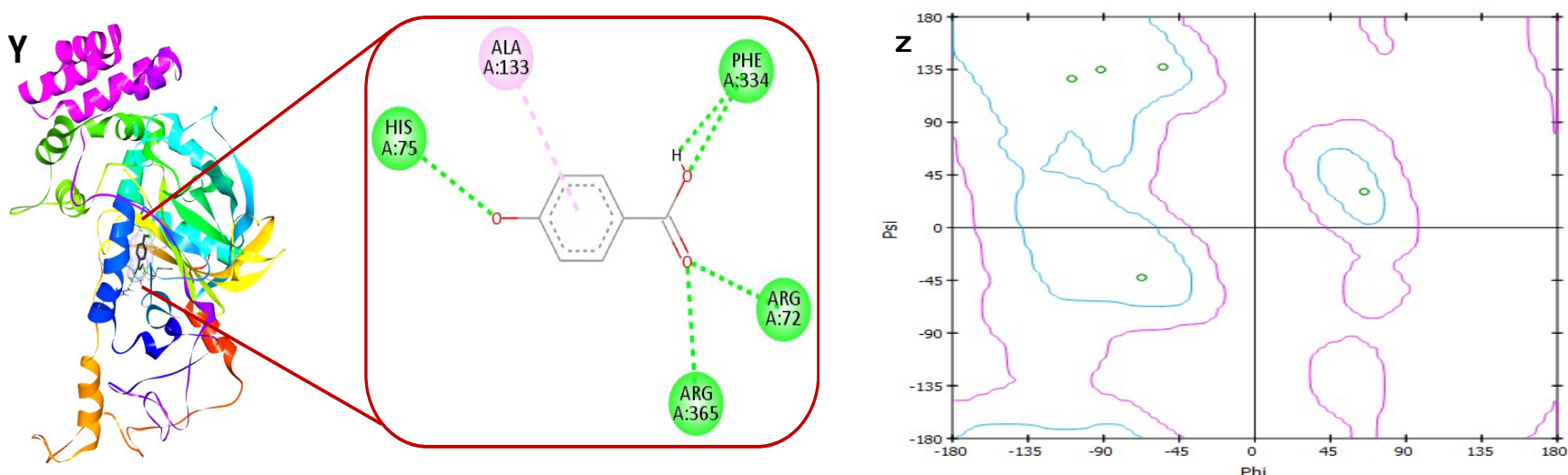

(7a) 1DGH and 4-hydroxybenzoic acid
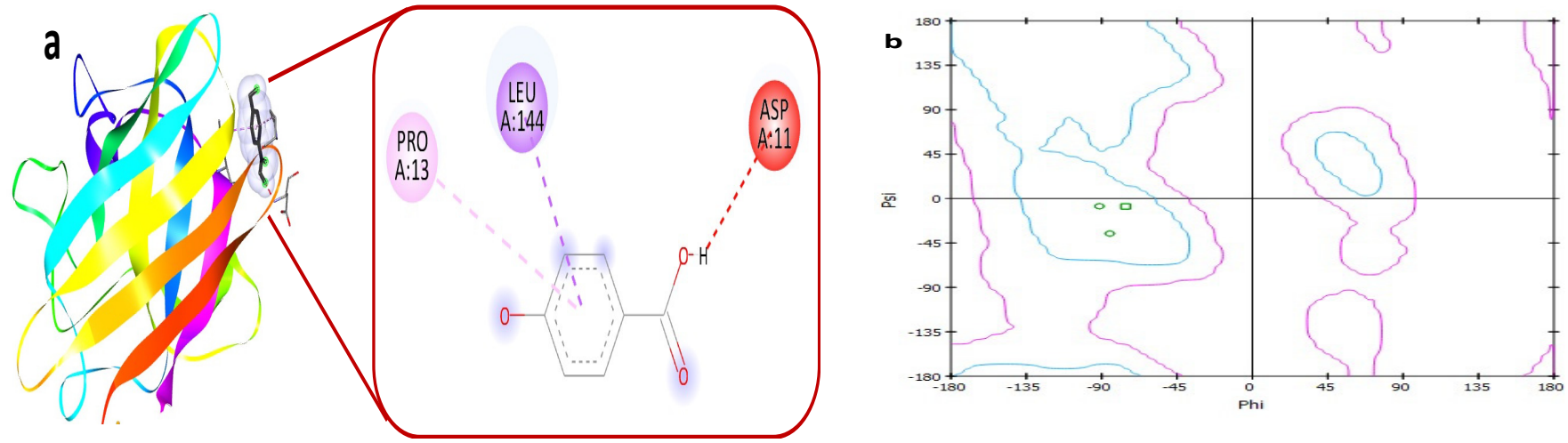

(7b) 5YTU and 4-hydroxybenzoic acid

Figure 12. Cont. 

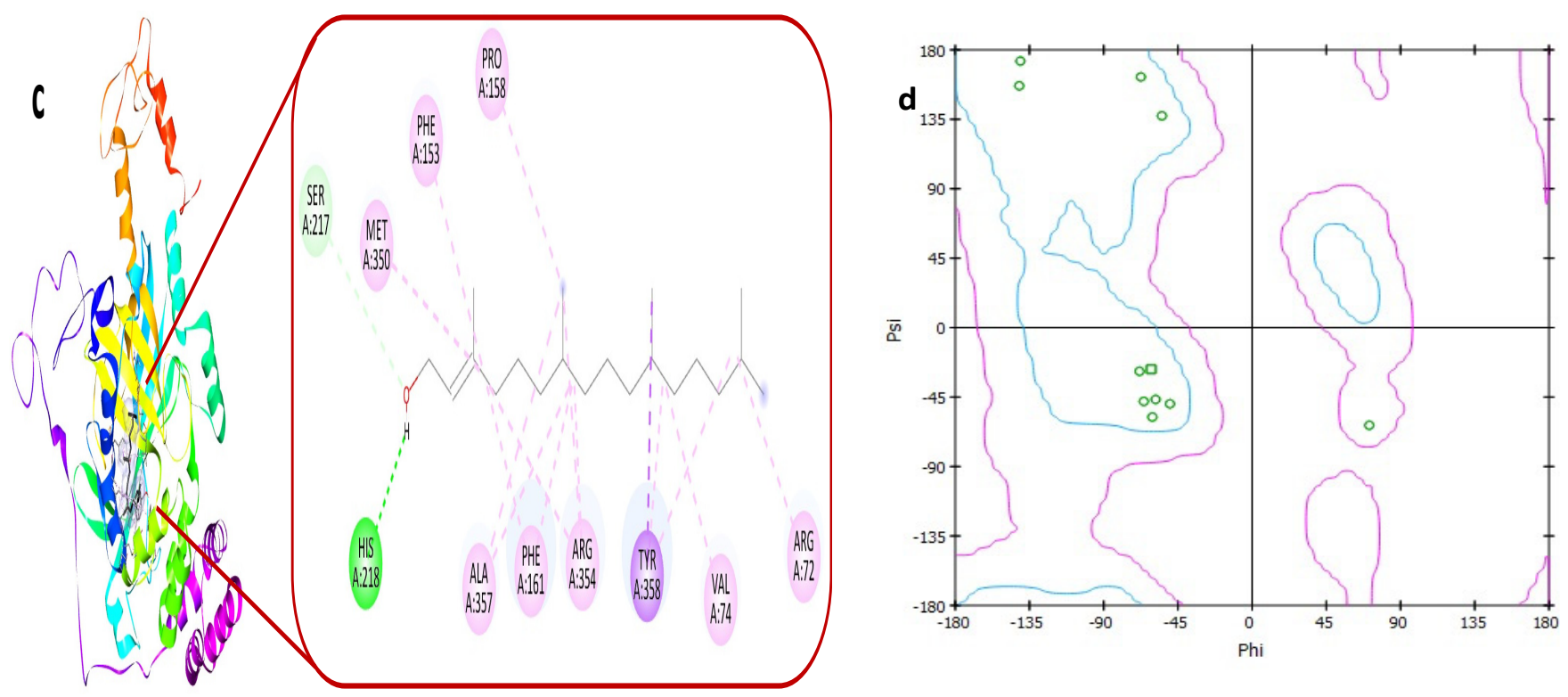

(8a) 1DGH and phytol
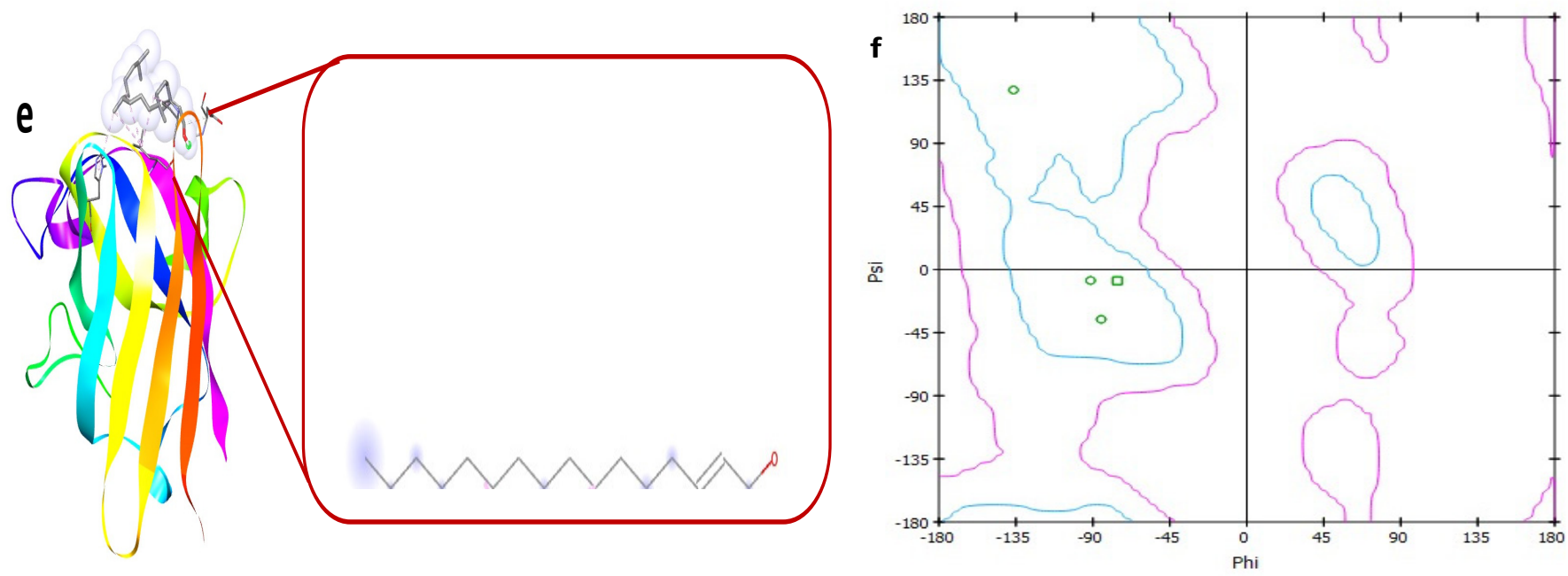

(8b) 5YTU and phytol
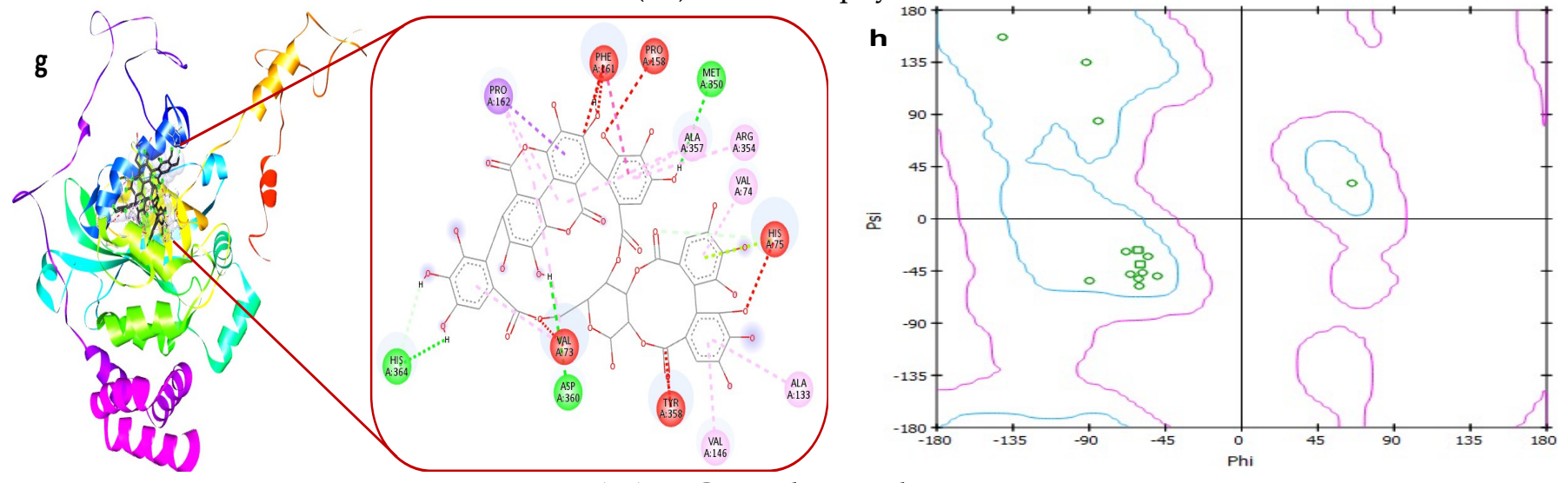

(9a) 1DGH and punicalagin

Figure 12. Cont. 

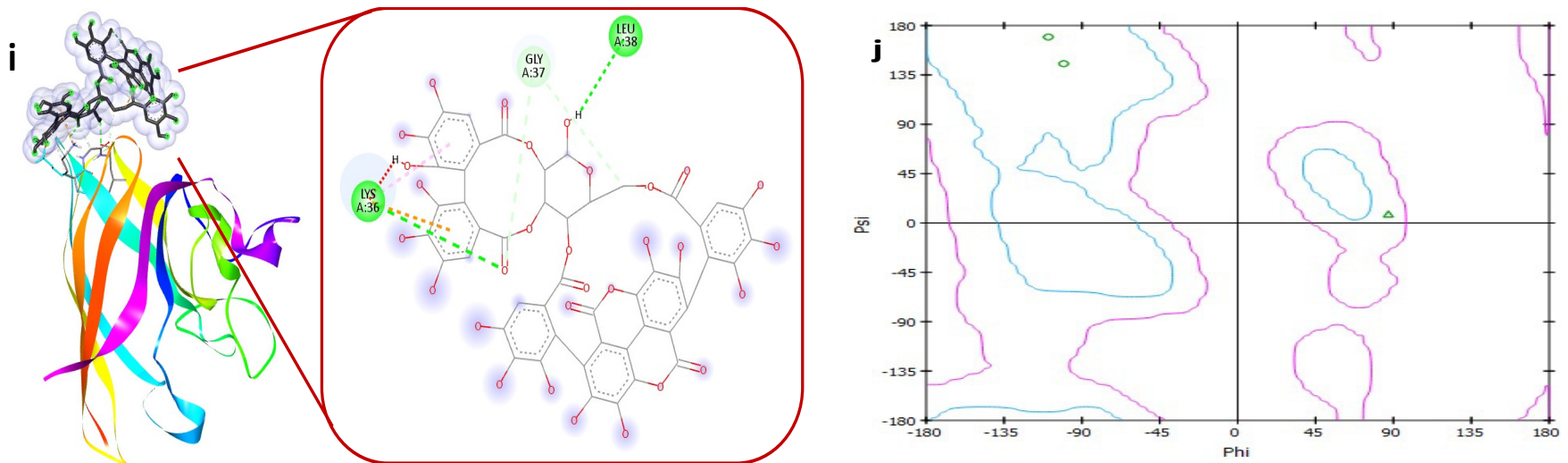

(9b) 5YTU and punicalagin
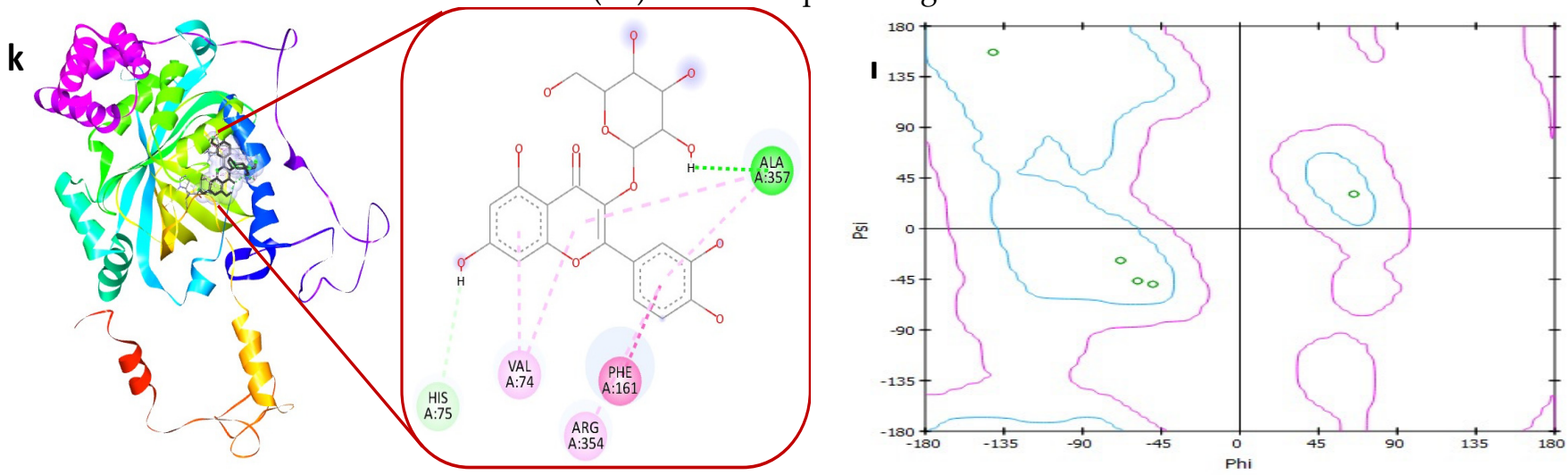

(10a) 1DGH and isoquercitrin
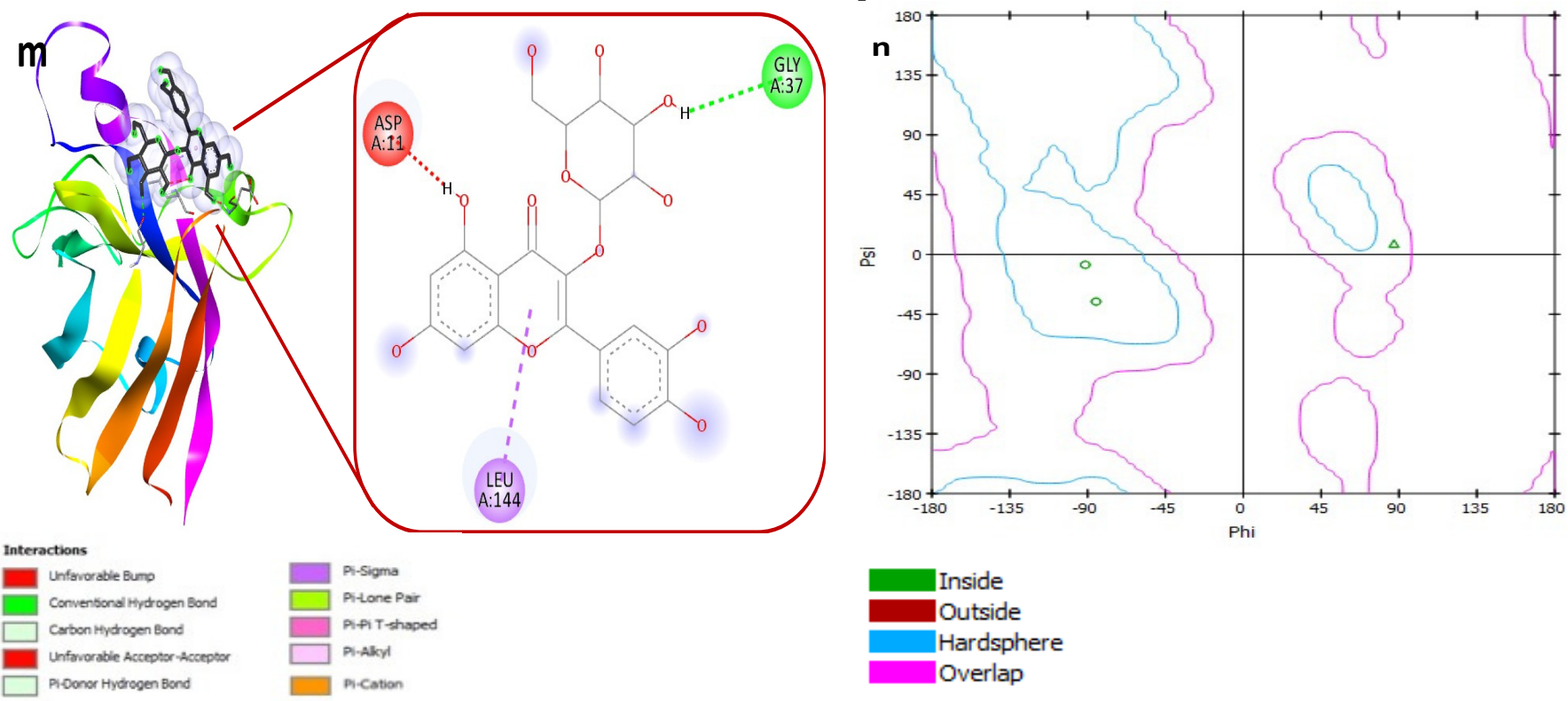

(10b) 5YTU and isoquercitrin

Figure 12. The molecular docking studies of antioxidant enzymes catalase (1DGH) and superoxide dismutase (5YTU) with active constituents of Ajwa date fruit with ligand (1) 3,3'-Di-O-methylellagic acid (A,C); ligand (2) rhamnetin (E,G); ligand (3) caffeic acid (I,K), ligand (4) ferulic acid (M,O), ligand (5) quercetin-rutinoside (Q,S); ligand (6) 6"' -malonylicariin (U,W), ligand (7) 4-hydroxybenzoic acid $(\mathbf{Y}, \mathbf{a})$, ligand (8) phytol (c,e); ligand (9) punicalagin $(\mathbf{g}, \mathbf{i})$; ligand $(\mathbf{1 0})$ isoquercitrin $(\mathbf{k}, \mathbf{m})$ and the Ramachandran plot of respective interactions are provided with each ligand-protein interaction $(\mathbf{B}, \mathbf{D}, \mathbf{F}, \mathbf{H}, \mathbf{J}, \mathbf{L}, \mathbf{N}, \mathbf{P}, \mathbf{R}, \mathbf{T}, \mathbf{V}, \mathbf{X}, \mathbf{Z}, \mathbf{b}, \mathbf{d}, \mathbf{f}, \mathbf{h}, \mathbf{j}, \mathbf{l}$ and $\mathbf{n})$. 


\section{Discussion}

Most diseases lead to a decrease in antioxidant defense, thromboembolic consequences, systemic hyper-inflammatory reactions, and the production of reactive oxygen species (ROS), neutrophil invasion, resulting in lysosomal membrane permeabilization. The release of ROS into the cytosol activates of the NLRP3 inflammasome. The NLRP3 inflammasome has been implicated in a number of inflammatory conditions through activation of caspase1 and release IL-1 [42]. Regarding the substantial morbidity and mortality associated with different diseases including diabetic patients, there are no definite treatments or entirely preventive strategies. As a result, there is an increasing need to uncover the pathobiological processes linked with elevated risk for different diseases and infections to develop a therapeutic strategy.

Various natural products including fruits and their seeds have been used in complementary and alternative medicine (CAM) to protect or alleviate stress, sickness, and to lessen or avoid adverse effects and symptoms, or manage or treat diseases [43]. Fruit wastes are another significant source of high-value bioactive compounds [44]. Date fruit and seed are both considered to be rich sources of various nutrients. Date fruit and seed are both considered as a part of nutrition. Date fruit flesh is solely consumed since it is edible, and the seed half is thrown away as trash. Date seed, on the other hand, has been claimed to be even more healthy, having high nutrients, excellent fatty acids, and a high energy value [45]. A date seed extract has been further claimed to have protective effects against toxicity caused by reactive oxygen species. This inhibitory activity against various reactive oxygen species may be linked with antioxidants present in the extract $[19,46]$.

The receptor, angiotensin-converting enzyme 2 (ACE2), expression is enhanced in patients with diabetes and hypertension who are treated with ACE inhibitors or angiotensin II receptor blockers. In addition, Sartore proposed that glycation of ACE2 has a direct impact on the pathomechanism of COVID-19, and 34 lysine residues are accessible. However, at least one of these residues leads to hydrogen bond's interaction with the receptor-binding domain (RBD) [47]. Furthermore, the tertiary structure of the protein is altered as a result of the glycation of ACE2 molecule residues. This modification adds to the overexpression or variation in activity of receptor. According to several studies, glycation of CD147 enhances the production of metalloproteinases leading to the relaxing of lung tissue and facilitating the invasion of the virus [48]. Our data show that Ajwa seed methanol extract reduced the browning intensity, aggregation index, and amyloid structures as compared to control samples. Hence, Ajwa seed extract can reduce the complications linked with diabetes, and glycation is occurring in COVID-19 patients.

A damaged endothelium caused by diabetes may predispose a sufferer to more severe complications and infections, as it has been suggested that the endothelial cells in a similar manner to respiratory cells use the ACE2 receptor, causing inflammation in these cells in patients with COVID-19 infection because inflammatory changes affect the endothelium throughout the body [49]. However, Ajwa seed and fruit pulp extract has exhibited a significant reduction in the heat-induced and hyposaline-induced denaturation of proteins and stabilized the HRBC membrane. Thus, Ajwa can be helpful in stabilizing the membranes and the reduction of the denaturation of proteins associated with inflammatory diseases including SARS-CoV-2 infection.

Oxidative stress has an impact on repair processes as well as the immunological control system. As a result, oxidative stress is a key contributor to pathogenesis. It proposes that antioxidant supplements should be included in different disease treatment methods. There is a strong relationship between pro-inflammatory components and reactive oxygen species (ROS) in many diseases, including SARS-CoV-2 infection, which is linked with inflammation and oxidative stress [50]. Hydroxyl free radicals are amongst the most prevalent ROS and have been linked to a variety of fatal illnesses, including cancer. The production of hydroxyl free radicals in the blood caused by the breakdown of $\mathrm{H}_{2} \mathrm{O}_{2}$ has already been linked to DNA damage and the promotion of carcinogenesis. Furthermore, hydroxyl radicals have the ability to activate oncogenes such as C-Raf-1 and K-ras [51]. In 
our study, Ajwa seed and fruit pulp extract have been found to have significant antioxidant potential by DPPH scavenging and $\mathrm{H}_{2} \mathrm{O}_{2}$ reducing activities. Therefore, Ajwa seed and fruit pulp extract can be helpful against most diseases.

Our data show that Ajwa seed extract has excellent antibacterial activity against both gram-positive and negative bacteria. Antioxidant enzymes make an important defense strategy against the pathology of several diseases. However, glycation may deactivate these enzymes [10,11]. Catalase and superoxide dismutase are important antioxidant enzymes of the human body. The deficient level of these enzymes has been reported to contribute significantly to oxidative stress-induced damage susceptibility of various important tissues and cells like pancreatic $\beta$-cells. Ajwa fruit pulp and seed contain several bioactive compounds. The mechanisms of Ajwa accountable for the prevention of diseases still have not been identified but are probably linked to their specific structures. To verify the mode of action of the potential chemical constituents of Ajwa in preventing oxidative stress and denaturation of antioxidant enzymes, and to link the promising molecules of Ajwa to their chemical characteristics, we performed a molecular docking study. In our molecular docking analysis, we took ten bioactive compounds of Ajwa as ligands and investigated the possible interaction of these ligands with two antioxidant enzymes including superoxide dismutase and catalase. Our docking study proved the interaction of these ligands and enzymes. Thus, these ligands might have the capability to protect these enzymes from denaturation caused by glycation. This further confirms our hypothesis that Ajwa seed and fruit extract may protect from oxidative stress in different diseases. Thus, the results of molecular docking studies verify the role of Ajwa in preventing disease progression.

In the most recent viral outbreaks of COVID-19 and SARS-CoV, there are several scientific reports on the positive benefits of traditional Chinese medicine (TCM), and certain polyphenolic substances have been suggested in this regard. Moreover, the antiviral effectiveness of TCM herbal extracts can be ascribed to their active components including baicalein and quercetin that are supposed to decrease COVID-19 by several possible mechanisms [52] such as decreasing NF- $\kappa$ B signaling and 3CLpro activity [53]. Our study confirms the health beneficial effects of Ajwa against the pathophysiology of various diseases that might be involved in the severity and mortality linked with SARS-COV-2 infection in diabetic conditions through in vitro studies. Therefore, the consumption of whole fruit along with seed extract of locally cultivated date palm (Ajwa variety) can be recommended regarding disease prevention. However, it is very important to identify and validate the mechanisms of Ajwa seed ingredients in modulating these diseases.

\section{Conclusions}

The in vitro experiment shows that Ajwa fruit pulp and seed extract possess antioxidant activities, show excellent protective potential against heat-induced albumin and egg albumin denaturation, and stabilize HRBC membrane. Besides, the seed extract inhibits glucose-mediated browning of BSA and cross-amyloid structures formation, AGE formation, and has antibacterial activities. Further, the molecular docking study proved the interaction between human antioxidant enzymes constituents of Ajwa fruit pulp and seed constituents that target the functional residues. Thus, Ajwa components may help in fighting oxidative stress-mediated complications, even in COVID-19 patients. In a nutshell, we can conclude that Ajwa fruit and seed are involved in various health-promoting mechanisms that may be beneficial against the severity of different disease management.

Author Contributions: Conceptualization, S.A. and A.H.R.; Funding acquisition, F.M.A., A.A., K.S.A. and S.A.A.; Investigation, M.A.A.; Methodology, M.A.A., R.R. and S.A.; Supervision, M.A.A., A.A., A.A.K. and K.S.A.; writing-original draft, S.A., R.R. and A.H.R.; writing-review \& editing, M.A.A., F.M.A., H.A., A.A., A.A.K., K.S.A., S.A.A. and A.H.R. All authors have read and agreed to the published version of the manuscript.

Funding: This research received no external funding.

Institutional Review Board Statement: Not applicable. 


\section{Informed Consent Statement: Not applicable.}

Data Availability Statement: All data generated or analyzed during this study are included in this published article.

Acknowledgments: The researchers would like to thank the Deanship of Scientific Research, Qassim University for funding the publication of this project.

Conflicts of Interest: The authors declare no conflict of interest for this work.

\section{References}

1. Hussain, A.; Bhowmik, B.; do Vale Moreira, N.C. COVID-19 and diabetes: Knowledge in progress. Diabetes Res. Clin. Pract. 2020, 162, 108142. [CrossRef] [PubMed]

2. Cerf, M.E. Beta cell dysfunction and insulin resistance. Front. Endocrinol. 2013, 4, 37. [CrossRef] [PubMed]

3. Hatting, M.; Tavares, C.D.J.; Sharabi, K.; Rines, A.K.; Puigserver, P. Insulin regulation of gluconeogenesis. Ann. N. Y. Acad. Sci. 2018, 1411, 21-35. [CrossRef] [PubMed]

4. Younus, H.; Anwar, S. Prevention of non-enzymatic glycosylation (glycation): Implication in thetreatment of diabetic complication. Int. J. Health Sci. 2016, 10, 261-277. [CrossRef]

5. Giacco, F.; Brownlee, M. Oxidative stress and diabetic complications. Circ. Res. 2010, 107, 1058-1070. [CrossRef]

6. Anwar, S.; Khan, S.; Almatroudi, A.; Khan, A.A.; AlSahli, M.A.; AlMatroodi, S.A.; Rahmani, A.H. A review on mechanism of inhibition of advanced glycation end products formation by plant derived polyphenolic compounds. Mol. Biol. Rep. 2021, 48, 787-805. [CrossRef]

7. Ramasamy, R.; Vannucci, S.J.; Yan, S.S.; Herold, K.; Yan, S.F.; Schmidt, A.M. Advanced glycation end products and RAGE: A common thread in aging, diabetes, neurodegeneration, and inflammation. Glycobiology 2005, 15, 16R-28R. [CrossRef]

8. Szaleczky, E.; Prechl, J.; Fehér, J.; Somogyi, A. Alterations in enzymatic antioxidant defence in diabetes mellitus-A rational approach. Postgrad. Med. J. 1999, 75, 13-17. [CrossRef]

9. Delgado-Roche, L.; Mesta, F. Oxidative Stress as Key Player in Severe Acute Respiratory Syndrome Coronavirus (SARS-CoV) Infection. Arch. Med. Res. 2020, 51, 384-387. [CrossRef]

10. Khan, M.A.; Anwar, S.; Alijarbou, A.A.; Al-Orainy, M.; Aldebasi, Y.H.; Islam, S.; Younus, H. Protective effect of thymoquinone on glucose or methylglyoxal-induced glycation of superoxide dismutase. Int. J. Biol. Macromol. 2014, 65, 16-20. [CrossRef] [PubMed]

11. Anwar, S.; Khan, M.A.; Sadaf, A.; Younus, H. A structural study on the protection of glycation of superoxide dismutase by thymoquinone. Int. J. Biol. Macromol. 2014, 69, 476-481. [CrossRef] [PubMed]

12. Anwar, S.; Younus, H. Inhibitory effect of alliin from Allium sativum on the glycation of superoxidedismutase. Int. J. Biol. Macromol. 2017, 103, 182-193. [CrossRef]

13. Anwar, S.; Younus, H. Antiglycating potential of ellagic acid against glucose and methylglyoxal induced glycation of superoxide dismutase. J. Proteins Proteom. 2017, 8, 1-12.

14. Younus, H.; Anwar, S. Antiglycating activity of Aloe vera gel extract and its active component aloin. J. Proteins Proteom. 2018, 9, 115-125.

15. Tabatabaei-Malazy, O.; Abdollahi, M.; Larijani, B. Beneficial Effects of Anti-Oxidative Herbal Medicines in Diabetic Patients Infected with COVID-19: A Hypothesis. Diabetes Metab. Syndr. Obes. 2020, 13, 3113-3116. [CrossRef]

16. Assirey, E.A. The chemical composition, total phenolic and antioxidant content of four date palm saudi cultivars. J. Taibah Univ. Sci. 2021, 15, 282-287. [CrossRef]

17. Rahmani, A.H.; Aly, S.M.; Ali, H.; Babiker, A.Y.; Srikar, S.; Khan, A.A. Therapeutic effects of date fruits (Phoenix dactylifera) in the prevention of diseases via modulation of anti-inflammatory, anti-oxidant and anti-tumour activity. Int. J. Clin. Exp. Med. 2014, 7, 483-491.

18. Dar, A.M.; Mir, S. Molecular docking: Approaches, types, applications and basic challenges. J. Anal. Bioanal. Tech. 2017, 8, 1-3. [CrossRef]

19. Anwar, S.; Almatroudi, A.; Allemailem, K.S.; Jacob Joseph, R.; Khan, A.A.; Rahmani, A.H. Protective Effects of Ginger Extract against Glycation and Oxidative Stress-Induced Health Complications: An In Vitro Study. Processes 2020, 8, 468. [CrossRef]

20. Anwar, S.; Almatroodi, S.A.; Almatroudi, A.; Allemailem, K.S.; Joseph, R.J.; Khan, A.A.; Alrumaihi, F.; Alsahli, M.A.; Rahmani, A.H. Biosynthesis of silver nanoparticles using Tamarixarticulata leaf extract: An effective approach for attenuation of oxidative stress mediated diseases. Int. J. Food Prop. 2021, 24, 677-701. [CrossRef]

21. Ruch, R.J.; Cheng, S.J.; Klaunig, J.E. Prevention of cytotoxicity and inhibition of intercellular communication by antioxidant catechins isolated from Chinese green tea. Carcinogeesis 1989, 10, 1003-1008. [CrossRef]

22. Alsahli, M.A.; Almatroodi, S.A.; Almatroudi, A.; Khan, A.A.; Anwar, S.; Almutary, A.G.; Alrumaihi, F.; Rahmani, A.H. 6-Gingerol, a Major Ingredient of Ginger Attenuates Diethylnitrosamine-Induced Liver Injury in Rats through the Modulation of Oxidative Stress and Anti-Inflammatory Activity. Mediat. Inflamm. 2021, 2021, 6661937. [CrossRef] [PubMed]

23. Almatroodi, S.A.; Almatroudi, A.; Anwar, S.; Babiker, A.Y.; Khan, A.Y.; Alsahli, M.A.; Rahmani, A.H. Antioxidant, antiinflammatory and hepatoprotective effects of olive fruit pulp extract: In vivo and in vitro study. J. Taibah Univ. Sci. 2020, 14, 1660-1670. [CrossRef] 
24. Almatroodi, S.A.; Anwar, S.; Almatroudi, A.; Khan, A.A.; Alrumaihi, F.; Alsahli, M.A.; Rahmani, A.H. Hepatoprotective Effects of Garlic Extract against Carbon Tetrachloride (CCl4)-Induced Liver Injury via Modulation of Antioxidant, Anti-Inflammatory Activities and Hepatocyte Architecture. Appl. Sci. 2020, 10, 6200. [CrossRef]

25. Sakat, S.S.; Juvekar, A.R.; Gambhire, M.N. In Vitro antioxidant and anti-inflammatory activity of methanol extract of Oxalis corniculata linn. Int. J. Pharm. Pharm. Sci. 2010, 2, 146-155.

26. Chanda, S.; Juvekar, A. In vitro anti-inflammatory activity of syringic acid. Int. J. Pharm. Pharm. Sci. 2019, 11, 71-73. [CrossRef]

27. Brownlee, M.; Vlassara, H.; Kooney, A.; Ulrich, P.; Cerami, A. Aminoguanidine prevents diabetesinduced arterial wall protein cross-linking. Science 1986, 232, 1629-1632. [CrossRef] [PubMed]

28. Kumar, D.; Ali, A. Antiglycation and antiaggregation potential of thymoquinone. Nat. Volatiles Essent. Oils 2019, 6, $25-33$.

29. Klunk, W.E.; Jacob, R.F.; Mason, R.P. Quantifying amyloid beta-peptide (Abeta) aggregation using the Congo red-Abeta (CR-abeta) spectrophotometric assay. Anal. Biochem. 1999, 266, 66-76. [CrossRef] [PubMed]

30. Kim, S.; Chen, J.; Cheng, T.; Gindulyte, A.; He, J.; He, S.; Li, Q.; Shoemaker, B.A.; Thiessen, P.A.; Yu, B.; et al. PubChem in 2021: New data content and improved web interfaces. Nucleic Acids Res. 2021, 49, D1388-D1395. [CrossRef] [PubMed]

31. Trott, O.; Olson, A.J. AutoDock Vina: Improving the speed and accuracy of docking with a new scoring function, efficient optimization and multithreading. J. Comput. Chem. 2010, 31, 455-461. [CrossRef]

32. BIOVIA. Dassault Systèmes, Discovery Studio Visualizer, DS Visualizer Client (Windows 64 Bit); Dassault Systèmes: San Diego, CA, USA, 2021; Available online: https:/ / discover.3ds.com/discovery-studio-visualizer-download/ (accessed on 18 June 2021).

33. Morris, G.M.; Huey, R.; Lindstrom, W.; Sanner, M.F.; Belew, R.K.; Goodsell, D.S.; Olsonet, A.J. AutoDock4 and AutoDockTools4: Automated docking with selective receptor flexibility. J. Comp. Chem. 2009, 30, 2785-2791. [CrossRef] [PubMed]

34. Alam, M.N.; Bristi, N.J.; Rafiquzzaman, M. Review on in vivo and in vitro methods evaluation of antioxidant activity. Saudi Pharm. J. 2013, 21, 143-152. [CrossRef]

35. Gulcin, İ. Antioxidants and antioxidant methods: An updated overview. Arch. Toxicol. 2020, 94, 651-715. [CrossRef]

36. Hanuka Katz, I.; Eran Nagar, E.; Okun, Z.; Shpigelman, A. The Link between Polyphenol Structure, Antioxidant Capacity and Shelf-Life Stability in the Presence of Fructose and Ascorbic Acid. Molecules 2020, 25, 225. [CrossRef] [PubMed]

37. Khan, M.A.; Siddiqui, S.; Ahmad, I.; Singh, R.; Mishra, D.P.; Srivastava, A.N.; Ahmad, R. Phytochemicals from Ajwa dates pulp extract induce apoptosis in human triple-negative breast cancer by inhibiting AKT/mTOR pathway and modulating Bcl-2 family proteins. Sci. Rep. 2021, 11, 10322. [CrossRef] [PubMed]

38. Alshwyeh, H.A. Phenolic profiling and antibacterial potential of Saudi Arabian native date palm (Phoenix dactylifera) cultivars. Int. J. Food Prop. 2020, 23, 627-638. [CrossRef]

39. Hamad, I.; AbdElgawad, H.; Al Jaouni, S.; Zinta, G.; Asard, H.; Hassan, S.; Hegab, M.; Hagagy, N.; Selim, S. Metabolic Analysis of Various Date Palm Fruit (Phoenix dactylifera L.) Cultivars from Saudi Arabia to Assess Their Nutritional Quality. Molecules 2015, 20, 13620-13641. [CrossRef]

40. Khalid, S.; Khalid, N.; Khan, R.S.; Ahmed, H.; Ahmad, A. A review on chemistry and pharmacology of Ajwa date fruit and pit. Trends Food Sci. Technol. 2017, 63, 60-69. [CrossRef]

41. Ramachandran, G.N.; Ramakrishnan, C.; Sasisekharan, V. Stereochemistry of polypeptide chain configurations. J. Mol. Biol. 1963, 7, 95-99. [CrossRef]

42. de la Lastra, J.M.P.; Andres-Juan, C.; Plou, F.J.; Perez-Lebeña, E. Impact of Zinc, Glutathione, and Polyphenols as Antioxidants in the Immune Response against SARS-CoV-2. Processes 2021, 9, 506. [CrossRef]

43. Anwar, S.; Almatroudi, A.; Alsahli, M.A.; Khan, M.A.; Khan, A.A.; Rahmani, A.H. Natural Products: Implication in Cancer Prevention and Treatment through Modulating Various Biological Activities. Anticancer Agents Med. Chem. 2020, 20, 2025-2040. [CrossRef] [PubMed]

44. Lucarini, M.; Durazzo, A.; Bernini, R.; Campo, M.; Vita, C.; Souto, E.B.; Lombardi-Boccia, G.; Ramadan, M.F.; Santini, A.; Romani, A. Fruit Wastes as a Valuable Source of Value-Added Compounds: A Collaborative Perspective. Molecules 2021, 26, 6338. [CrossRef] [PubMed]

45. Idowu, A.T.; Igiehon, O.O.; Adekoya, A.E.; Idowu, S. Dates palm fruits: A review of their nutritional components, bioactivities and functional food applications. AIMS Agric. Food 2020, 5, 734-755. [CrossRef]

46. Almatroodi, S.A.; Alsahli, M.A.; Almatroudi, A.; Anwar, S.; Verma, A.K.; Dev, K.; Rahmani, A.H. Cinnamon and its active compounds: A potential candidate in disease and tumour management through modulating various genes activity. Gene Rep. 2020, 21, 100966. [CrossRef]

47. Sartore, G.; Ragazzi, E.; Faccin, L.; Lapolla, A. A role of glycation and methylation for SARS-CoV-2 infection in diabetes? Med. Hypotheses 2020, 144, 110247. [CrossRef]

48. Abramczyk, U.; Kuzan, A. What Every Diabetologist Should Know about SARS-CoV-2: State of Knowledge at the Beginning of 2021. J. Clin. Med. 2021, 10, 1022. [CrossRef]

49. Varga, Z.; Flammer, A.J.; Steiger, P.; Haberecker, M.; Andermatt, R.; Zinkernagel, A.S.; Mehra, M.R.; Schuepbach, R.A.; Ruschitzka, F.; Moch, H. Endothelial cell infection and endotheliitis in COVID-19. Lancet 2020, 395, 1417-1418. [CrossRef]

50. Chernyak, B.V.; Popova, E.N.; Prikhodko, A.S.; Grebenchikov, O.A.; Zinovkina, L.A.; Zinovkin, R.A. COVID-19 and Oxidative Stress. Biochemistry 2020, 85, 1543-1553. [CrossRef] 
51. Alsahli, A.M.; Anwar, S.; Alzahrani, F.M.; Almatroudi, A.; Alfheeaid, H.; Khan, A.A.; Allemailem, K.S.; Almatroodi, S.A.; Rahmani, A.H. Health Promoting Effect of Phyllanthus emblica and Azadiractha indica against Advanced Glycation End Products Formation. Appl. Sci. 2021, 11, 8819. [CrossRef]

52. Yang, Y.; Islam, M.S.; Wang, J.; Li, Y.; Chen, X. Traditional Chinese Medicine in the Treatment of Patients Infected with 2019-New Coronavirus (SARS-CoV-2): A Review and Perspective. Int. J. Biol. Sci. 2020, 16, 1708-1717. [CrossRef] [PubMed]

53. Du, A.; Zheng, R.; Disoma, C.; Li, S.; Chen, Z.; Li, S.; Liu, P.; Zhou, Y.; Shen, Y.; Liu, S.; et al. Epigallocatechin-3-gallate, an active ingredient of Traditional Chinese Medicines, inhibits the 3CLpro activity of SARS-CoV-2. Int. J. Biol. Macromol. 2021, 176, 1-12. [CrossRef] [PubMed] 